\title{
The SNS High Energy Beam Transport Line
}

BNL/SNS TECHNICAL NOTE

NO. 052

D. Raparia, J. Alessi, Y. Y. Lee and W. T. Weng

September 20, 1998

ALTERNATING GRADIENT SYNCHROTRON DEPARTMENT BROOKHAVEN NATIONAL LABORATORY

UPTON, NEW YORK 11973 


\title{
The SNS High Energy Beam Transport Line
}

\author{
D. Raparia, J. Alessi, Y. Y. Lee, and W. T. Weng,
}

September 20, 1998

\section{Introduction}

The $1 \mathrm{MW}$ SNS machine consists of $1 \mathrm{GeV}$ linac, an accumulator ring [1], and two transfer lines: (a) High Energy Beam Transfer line (HEBT)[2] , and (b) Ring to Target Beam Transfer line (RTBT)[3]. A key feature of this accelerator is the requirement for low uncontrolled beam losses $(\mathrm{nA} / \mathrm{m})$ to allow hands on maintenance. To achieve such low beam losses, the beam must be prepared very carefully before injecting in to the accumulator. The HEBT not only matches the beam into the accumulator, but also determines the beam quality before injection. To reduce the probability of uncontrolled beam losses, HEBT is equipped with nine sets of beam halo scrapers. The ratio of aperture to rms beam size is kept greater than 15 . The maximum magnetic field in dipoles and quadrupoles is less than $3 \mathrm{kG}$ to keep the $\mathrm{H}^{-}$stripping losses low. Another key feature of this line ( to reduce the uncontrolled beam loss) is careful control of tolerances on elements. Figure 1 shows the HEBT. Table 1 gives the Twiss parameters at the entrance (middle of the last linac quadrupole) and exit (injection stripping foil) of the HEBT.

\section{Functions}

The HEBT has following functions: (a) matching of the beam from the linac into the transport line, (b) momentum selection, (c) adjusting the momentum spread, (d) proper matching for beam injection, (e) characterizarion of the beam, both out of the linac and before injection, ( $f$ ) halo cleanup, $(\mathrm{g})$ providing a beam dump for the linac.

We have managed to decouple the first four of these functions, and can consider the HEBT as having three sections: Linac-Achromat Matching Section (LAMS), Achromat, and Acromat-Ring Matching Section (ARMS). In addition to the $90^{\circ}$ bend to the ring there is a $0^{\circ}$ beam line used for linac beam characterization as shown in Figure 1. The first four FODO cells $(11.4 \mathrm{~m} /$ cell) after 


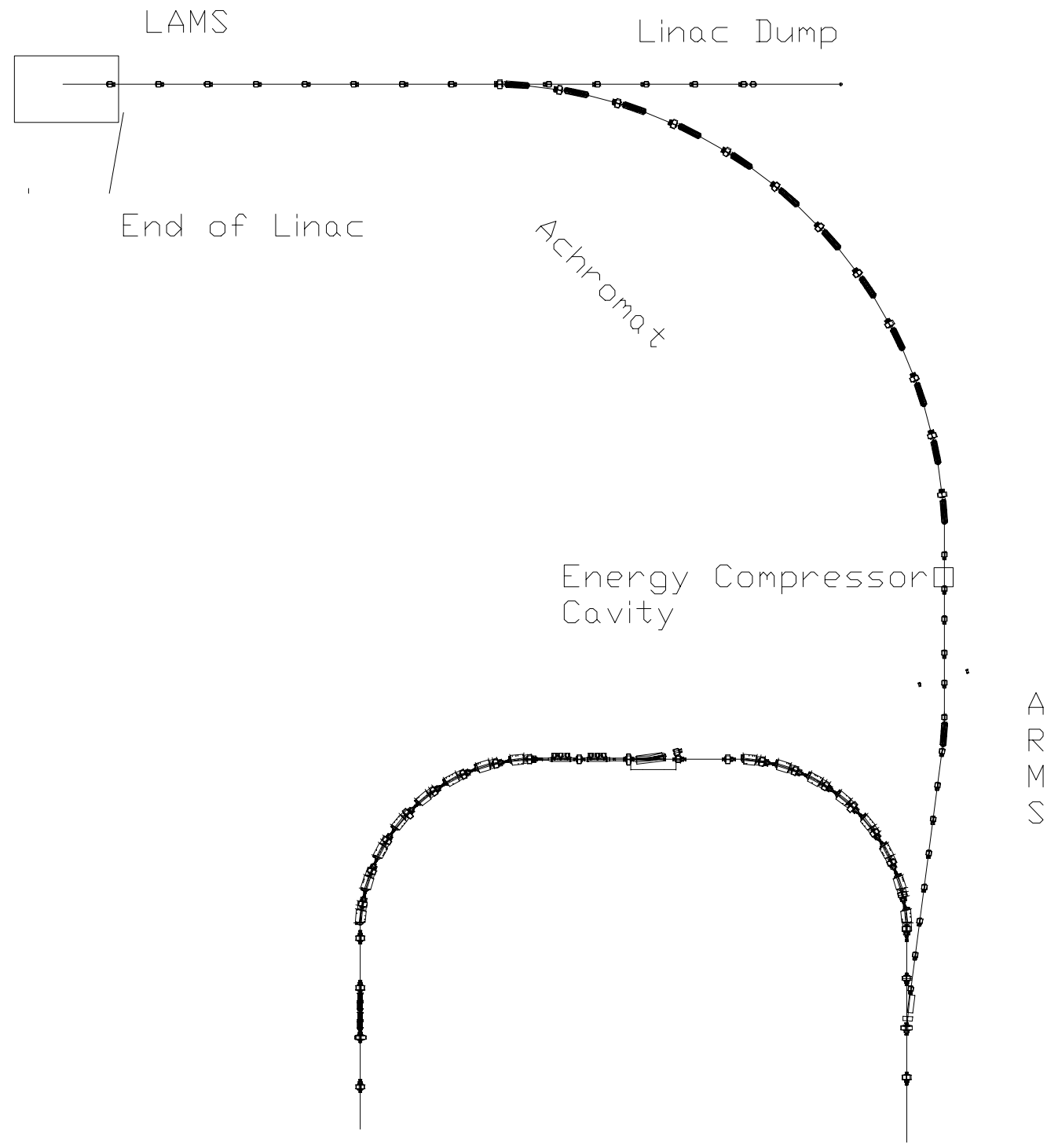

Figure 1: Layout of the HEBT. 
Table 1: Twiss Parameters at Entrance and Exit of the HEBT for 1 MW.

$\begin{array}{cccc}\text { Twiss par. } & \text { Entrance } & \text { Exit } & \text { Units } \\ & & & \\ \alpha_{x} & 0.00 & -1.955 & \mathrm{~mm} / \mathrm{mrad} \\ \beta_{x} & 12.811 & 15.690 & \\ \pi \epsilon_{x} & 0.70 & 0.70 & \pi \mathrm{mm} \mathrm{mrad}(\text { unnor,5RMS) } \\ \alpha_{y} & 0.00 & 0.7753 & \mathrm{~mm} / \mathrm{mrad} \\ \beta_{y} & 9.181 & 5.162 & \\ \pi \epsilon_{y} & 0.70 & 0.70 & \pi \mathrm{mm} \mathrm{mrad}(\text { unnor,5RMS) } \\ \alpha_{z} & 0.0005 & 0.14 & \mathrm{deg} / \mathrm{kev} \\ \beta_{z} & 0.005 & 0.05 & \pi \mathrm{keV} \mathrm{deg}(5 \mathrm{RMS}) \\ \pi \epsilon_{z} & 1500 . & 1500 & \end{array}$

the linac (LAMS) are used to characterize the linac beam, match the beam into the achromat, collimate the beam halo, and maintain space for a kicker required in a future upgrade to $4 \mathrm{MW}$ operation. Following this section, a six cell long achromat $(14 \mathrm{~m} /$ cell $)$ bends the beam $90^{\circ}$ and provides momentum selection by cleaning up the beam energy halo at the point of maximum dispersion $(\eta=8.9$ $\mathrm{m})$. The energy spreader cavity is located in the first cell following the achromat (in the ARMS), where the dispersion and its derivative are zero. The remaining six cells $(8 \mathrm{~m} /$ cell $)$ are used for matching the beam into the accumulator ring, diagnostics, and beam halo scrapers. A small dipole magnet, for steering the beam in the quadrupole focusing plane, follows every quadrupole in the HEBT.

To reduce the probability of uncontrolled losses, HEBT is equipped with nine sets of beam halo scrapers. The collimators are the miminum apertures in the line, chosen to be 15 times the rms beam size. The magnetic field in the dipoles and quadrupoles is kept less than $3 \mathrm{kG}$, to keep Lorentz stripping losses below $0.1 \mathrm{nA} / \mathrm{m}$.

Table 2 shows the calculated Lorentz stripping of $\mathrm{H}^{-}$in the line.

Table 3 shows the component specifications for the HEBT.

\subsection{Linac to Achromat Matching Section}

The linac has a FDOO lattice with a phase advance of about 5.3 degrees/meter (19 degrees/cell), and the achromat has a FODO lattice with a phase advance of 5.3 degrees/meter( 60 degrees/cell). To provide a smooth transition, the matching system uses the first two cells (four quadrupoles) of the HEBT. There are two movable and two fixed collimators located in the 2nd to 5th half cells to remove any beam halo coming out of the linac. The 6 th and 7 th half cell are kept for the kickers in a future upgrade. The space between quadrupoles in the 
Table 2: Lorenz Stripping of $\mathrm{H}^{-}$in HEBT

$\begin{array}{ccc}\text { B (Tesla) } & \begin{array}{c}\text { Fractional Loss } \\ \left(105^{\circ} \text { total bend }\right)\end{array} & \begin{array}{c}\text { Loss through } \\ \text { dipole region }(\mathrm{nA} / \mathrm{m})\end{array} \\ 0.3 & 5.7^{*} 10^{-6} & 0.06 \\ 0.35 & 2.4 * 10^{-4} & 2.6 \\ 0.4 & 3.9 * 10^{-3} & 4.3\end{array}$

Table 3: Component Specifications for the HEBT.

\begin{tabular}{|c|c|c|c|c|c|}
\hline Location & Type & Number & Field & Aperture & Length \\
\hline \multicolumn{6}{|c|}{ Dipole } \\
\hline ACHRO..ARMS & $7.50^{\circ}$ & 13 & $0.3 \mathrm{~T}$ & $8 \mathrm{~cm} \mathrm{gap}$ & $2.5 \mathrm{~m}$ \\
\hline LAMS,ARMS,LDUMP & Corr. & 25 & $0.03 \mathrm{~T}$ & $12 \mathrm{~cm} \times 12 \mathrm{~cm}$ & $0.2 \mathrm{~m}$ \\
\hline ACHRO. & Corr. & 12 & $0.03 \mathrm{~T}$ & $20 \mathrm{~cm} \times 20 \mathrm{~cm}$ & $0.3 \mathrm{~m}$ \\
\hline \multicolumn{6}{|c|}{ Quadrupole } \\
\hline LAMS,ARMS,LDUMP & $\mathrm{QF} / \mathrm{QD}$ & 25 & $4 \mathrm{~T} / \mathrm{m}$ & $12 \mathrm{~cm}$ dia. & $0.5 \mathrm{~m}$ \\
\hline ACHRO. & $\mathrm{QF} / \mathrm{QD}$ & 12 & $3.4 \mathrm{~T} / \mathrm{m}$ & $20 \mathrm{~cm}$ dia. & $0.5 \mathrm{~m}$ \\
\hline LDUMP & $\mathrm{QF} / \mathrm{QD}$ & 2 & $4 \mathrm{~T} / \mathrm{m}$ & $12 \mathrm{~cm}$ dia. & $0.8 \mathrm{~m}$ \\
\hline \multicolumn{6}{|c|}{ Energy Compressor } \\
\hline ARMS & 16 cell & 1 & $3.5 \mathrm{MV} / \mathrm{m}$ & $4.8 \mathrm{~cm} \mathrm{dia}$ & $2.6 \mathrm{~m}$ \\
\hline
\end{tabular}


first cell of the HEBT is used for diagnostics.

\subsection{Momentum Selection (Achromat)}

An achromatic bend of $90^{\circ}$, which is required by the facility foot-print, starts at the 5 th cell after the linac and finishes in six cells with twelve $7.5^{\circ}$ dipoles. The total phase advance in the achromat of $360^{\circ}$ provides achromaticity up to second order. The phase advance per cell is kept the same as in the LAMS, i.e. $60^{\circ}$ per cell.

The half-cell length is 7 meter, with a 2.5 long dipole $\left(7.5^{\circ}\right)$, a 0.5 meter long quadrupole, and a 3.5 meter drift. The 3.5 meter long drift will be required for a shielding wall in the achromat, and in the middle of the achromat will be used for a collimator. Although this 3.5 meter drift space is only needed in a couple of locations, choosing this 3.5 meter drift in every cell gives a symmetry and also helps to keep the dispersion high ( 8.9 meter).

A beam energy halo scraper is located at the middle cell, where the dispersion is maximum ( 8.9 meter). This provides a resolution

$$
R_{1} \equiv \frac{R 16}{2 X_{0} R 11} \equiv \frac{8.9}{2 \times \sqrt{18 \times 0.7 \times 10^{-6}} \times 1} \cong 1.3 \times 10^{3}
$$

and energy resolution $\sim 6 \mathrm{~mm} / \mathrm{MeV}$. The momentum acceptance of the achromat is $\pm 1 \%$. Figure 2 shows amplitude functions $\left(\beta_{x}, \beta_{y}\right)$ and dispersion function $\left(\eta_{x}\right)$ along the HEBT. The first dipole in the achromat is the switching magnet to provide beam to the straight linac dump.

\subsection{Momentum Spreader}

Spreading the momentum of the beam, for more stability in the accumulator ring, is accomplished with a 2.6 meter long, 16 rf cell cavity with an axial gradient of $3.5 \mathrm{MV} / \mathrm{m}$. This cavity is located in the first half cell after the the achromat (130 $\mathrm{m}$ from the linac), and is similar to the last cavity of linac. At this location the dispersion and its derivative are both zero. This location of the cavity can provide the desired momentum spread for a $1 \mathrm{MW}(28 \mathrm{~mA})$ beam as well as a $2 \mathrm{MW}(56 \mathrm{~mA}$ ) beam (see Figures 3 and 4 ). For beam stability in the accumulator one might like to have $\frac{\Delta P}{P} \cong 0.5 \%$. Table 4 shows the different values of $\frac{\Delta P}{P}$ that can be achieved by changing phase and amplitude of the cavity.

\subsection{Achromat Ring Matching Section}

This section consists of two subsections. The first subsection is two and half cells long and dispersion free. This subsection is needed to provide space for four collimators $\left(2 \mathrm{x}\right.$, and $2 \mathrm{y}$ ), four wire scanners about $60^{\circ}$ apart in betatron phase advance to measure emittance, and the energy spreader cavity. 


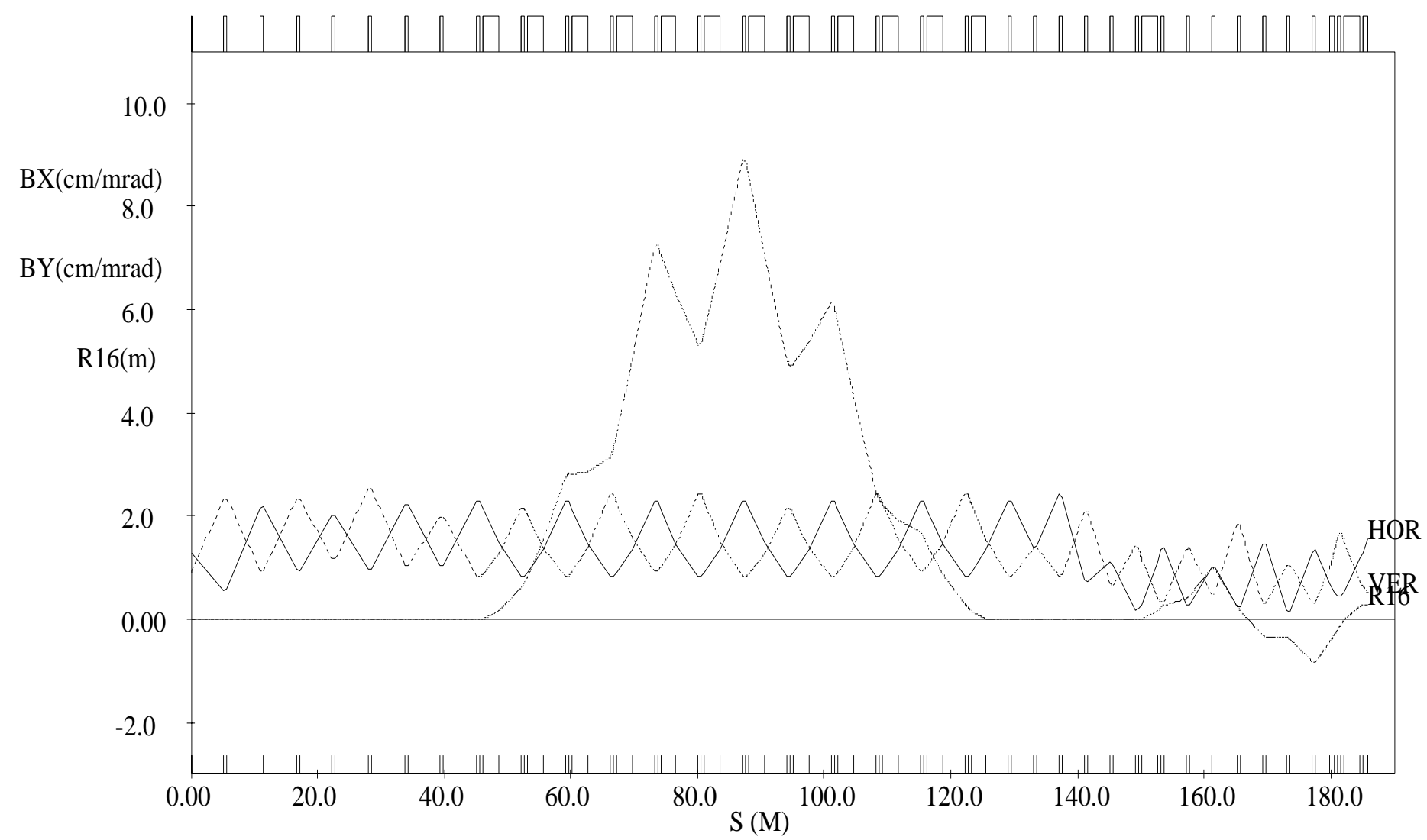

Figure 2: TRANSPORT output showing the amplitude $(\beta)$ functions and dispersion function $(\eta)$ along the HEBT

Table 4: Energy Spread at the Injection Foil

$\begin{array}{lllll}\begin{array}{l}\mathrm{E}_{0} \mathrm{~T} \\ (\mathrm{MV} / \mathrm{m})\end{array} & \begin{array}{l}\text { Phase } \\ (\mathrm{deg})\end{array} & \begin{array}{l}\text { Length } \\ (\mathrm{m})\end{array} & \begin{array}{l}\Delta \mathrm{E} \\ (\mathrm{MeV})\end{array} & \frac{\Delta P}{P} \\ 1.190 & -90 & 2.6 & 0.044 & 0.03 \times 10^{-3} \\ 0.0 & & 2.6 & 1.895 & 1.27 \times 10^{-3} \\ 1.190 & +90 & 2.6 & 3.815 & 2.57 \times 10^{-3} \\ 3.500 & +90 & 2.6 & 7.597 & 5.12 \times 10^{-3}\end{array}$



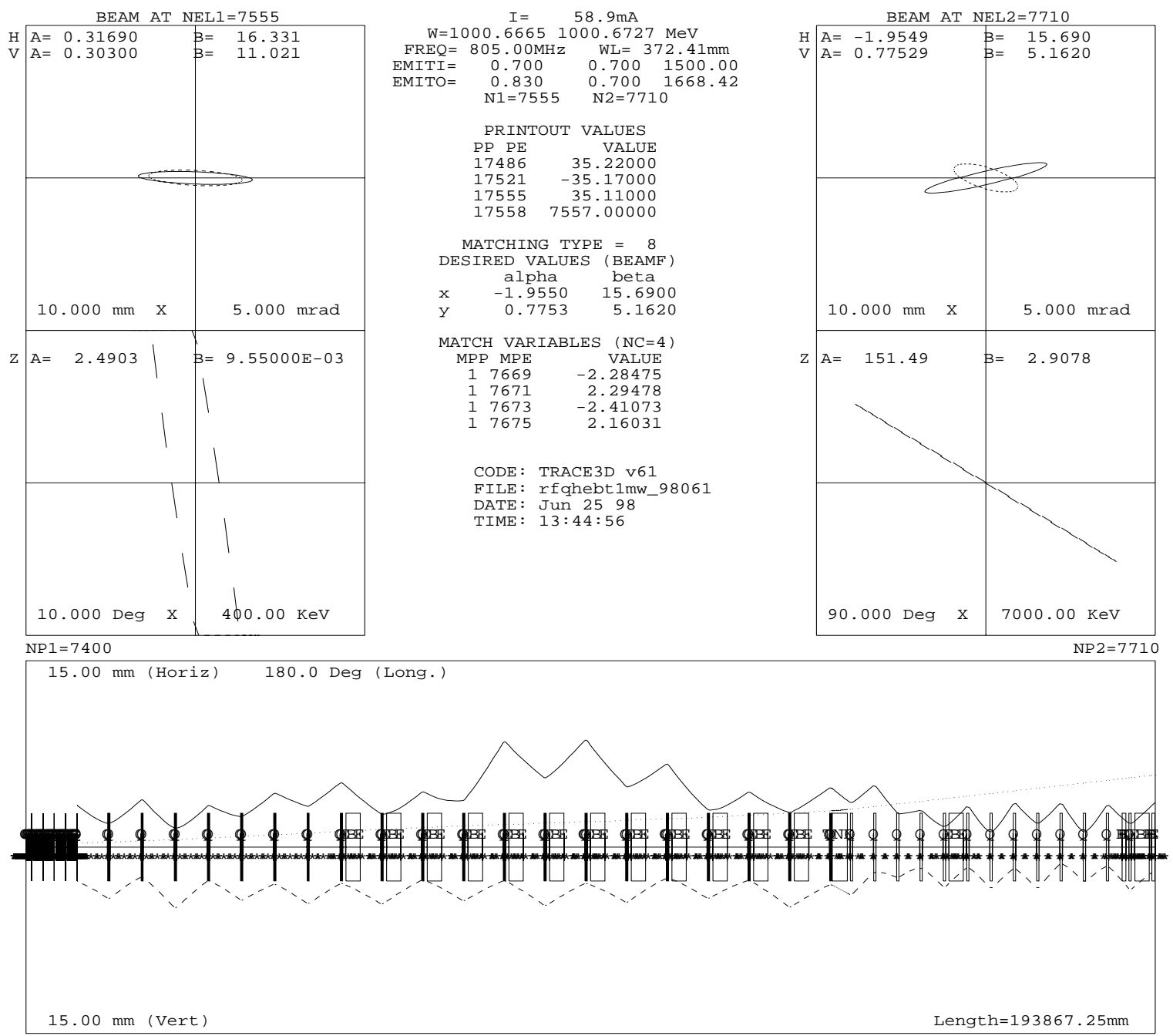

Figure 3: TRACE3D output for $1 \mathrm{MW}$ case. 

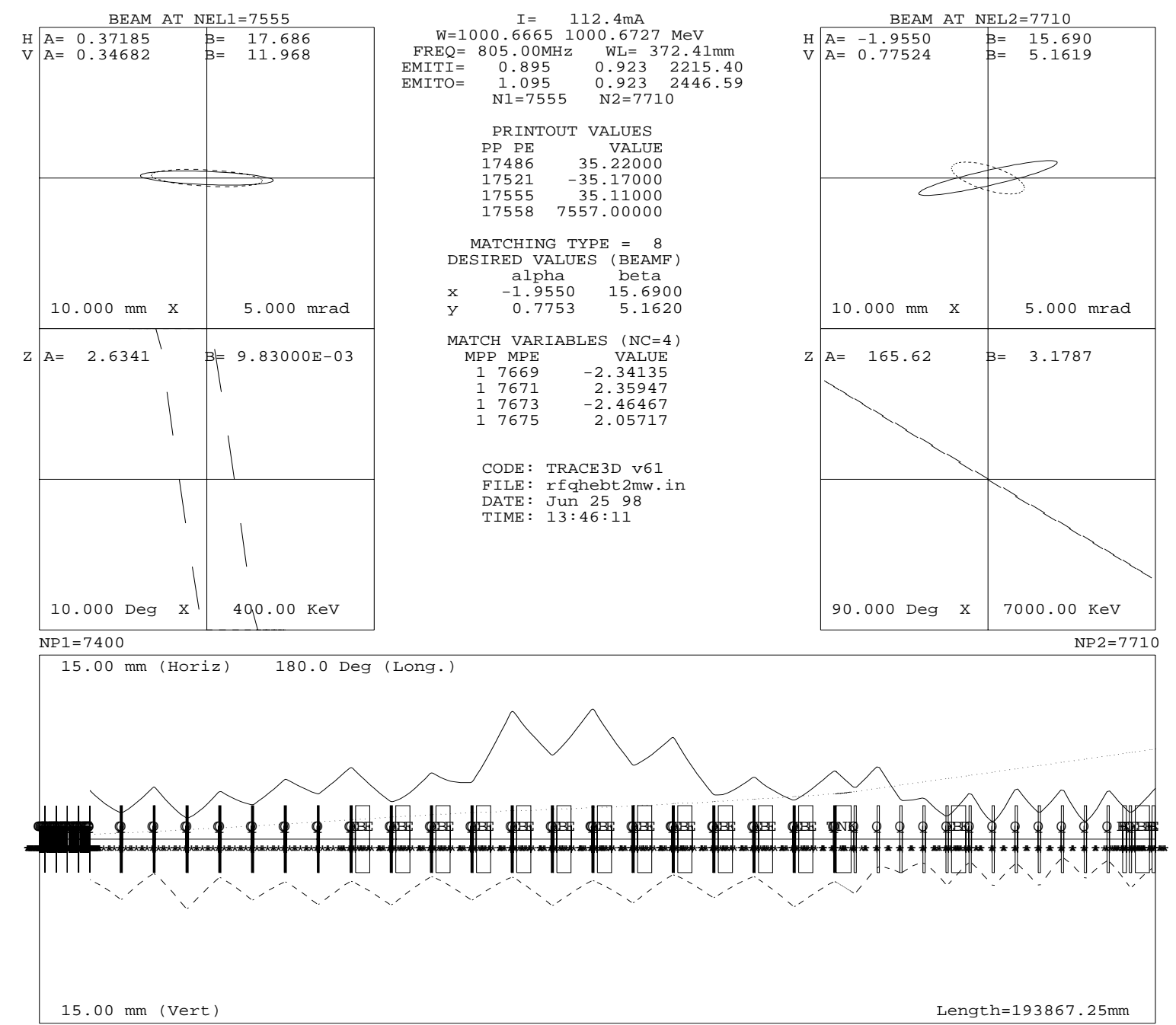

Figure 4: TRACE3D output for $2 \mathrm{MW}$ case. 
Table 5: Diagnostic Devices in the HEBT

$\begin{array}{ll}\text { Device } & \text { Number } \\ \text { Beam Loss Monitor } & 77 \\ \text { Current Toroid } & 4(1) \\ \text { Beam Position Monitor } & 33 \\ \text { Wall Current Monitor } & 3(1) \\ \text { Harp } & 2(1) \\ \text { Bunch Shape Monitor } & 2(1) \\ \text { Time of Flight } & 2(1) \\ \text { Wire Scanner } & 8(4)\end{array}$

At end of this subsection the line is parallel to the straight section of the ring, but $10 \mathrm{~m}$ off axis. To inject the beam into the ring the second four and half cells long subsection provides the required "dog leg". This second subsection, which starts with a $7.5^{\circ}$ dipole magnet, has to be $\geq 360^{\circ}$ long in betatron phase advance in order to provide a dispersion of only $0.28 \mathrm{~m}$, since this dog leg has opposite direction bends. There is no vertical bend and no vertical dispersion in the line. The locations of the dipoles are determine by the injection scheme. The phase advance in first two cells is slowly raised from $60^{\circ}$ to $90^{\circ}$ and is then kept at $90^{\circ}$ for the rest of the four and a half cells, which is the same as the ring. The cell length is kept the same as an accumulator ring arc cell, 8 meter per cell.

\subsection{Diagnostics}

In addition to the straight-ahead linac diagnostic line, there are enough diagnostic devices spread over the entire HEBT to determine beam losses and beam quality before injection. A list of the devices are shown in Table 5. (The number of devices in the parentheses will be provided by the Los Alamos.) There is one beam loss monitor per quadrupole and one per dipole, with another 27 left for additional critical locations. Beam position monitors (x and y) are located near each quadrupole. Harps, which will only be used at low repetition rate due to thermal constraints, will alow beam profile measurements to be made at the entrance to the achromat, the middle of the achromat, and entrance to the ring. Using profiles from crawling-wire profile minitors located between four consecutive quadrupole magnets, one can infer the beam emittance. There will be two of these four-profile units, one at exit of the linac, and one before the ring, in a dispersion-free region. Bunch shape monitors (detailed bunch shape), wall current monitors (continous monitoring of coarse bunch shape), and time of flight energy monitors (continuous monitoring of beam energy) will be located at the output of the linac and output of the energy spreader cavity (with an 
Table 6: Collimator Locations and Radii

$\begin{array}{lllllr}\text { Collimator } & \begin{array}{l}\text { Location } \\ \text { (Quad No) }\end{array} & \begin{array}{l}\beta_{x}, \beta_{y} \\ (\mathrm{~m})\end{array} & \begin{array}{l}\eta \\ (\mathrm{m})\end{array} & \begin{array}{l}\sigma \\ (\mathrm{Deg})\end{array} & \begin{array}{r}\text { Radius } \\ (\mathrm{mm})\end{array} \\ \text { H1 } & & & 0 & & \\ \text { V1 } & \text { Q1 } & 21.4 & 0 & 0 & 7.624 \\ \text { H2 } & \text { Q3 } & 23.4 & 0 & 30 & 7.931 \\ \text { V2 } & \text { Q4 } & 20.2 & 0 & 60 & 7.414 \\ \text { H3 } & \text { Q21 } & 14.0 & 0 & 90 & 8.289 \\ \text { V3 } & \text { Q22 } & 22.3 & 0 & 685 & 6.205 \\ \text { H4 } & \text { Q23 } & 23.8 & 0 & 655 & 7.779 \\ \text { V4 } & \text { Q24 } & 13.9 & 0 & 720 & 6.030 \\ \text { P1 } & \text { Q15 } & 22.0 & 8.9 & 420 & 52.238\end{array}$

additional wall current monitor at the entrance to the energy spreader cavity). Finally, current toroids will allow continuous monitoring of beam current at four locations. The diagnostics are shown in Figure 5.

\subsection{Halo Collimation}

There are a total of nine collimators in the HEBT, one for momentum collimation and eight for transverse collimation. Four transverse collimators ( 2 each in $\mathrm{x}$ and $\mathrm{y}$ ) are located just after the linac, with four others in a disperson free region just after the energy spreader cavity. Of these eight collimators, the four horizontal collimators are movable foils, to strip the $\mathrm{H}^{-}$to $\mathrm{H}^{+}$, which is then dumped, after horizontal defocusing, in the same dump that is used for fixed vertical collimation. This reduces costs, and has the added advantage of being adjustable in the bending plane. The momentum collimator is located at the maximum dispersion point in the achromat. This scraper is a pair of movable stripping foils in the middle of the bend section, followed by an off-line beam dump for oppositely bent protons. All collimators are designed to handle $10^{-3}$ of the beam, but we expect any one to intercept less than $10^{-4}$. Details of the collimators are given [4], and the configuration for these collimators is shown schematically in Figure 6.

Figure 7 shows the emittance as a function of beam fraction for the end-toend simulated beam, and for a Gaussian beam having the same rms emittance. The collimator radius is chosen according following formula such that $10^{-4}$ of the beam intersects each collimator.

$$
R_{\mathrm{COL}}=\sqrt{18.4 \times \epsilon_{R M S} \beta}+\eta \frac{\Delta P(0.5 \%)}{P}+0.2 \mathrm{~mm}(\text { centroid })
$$




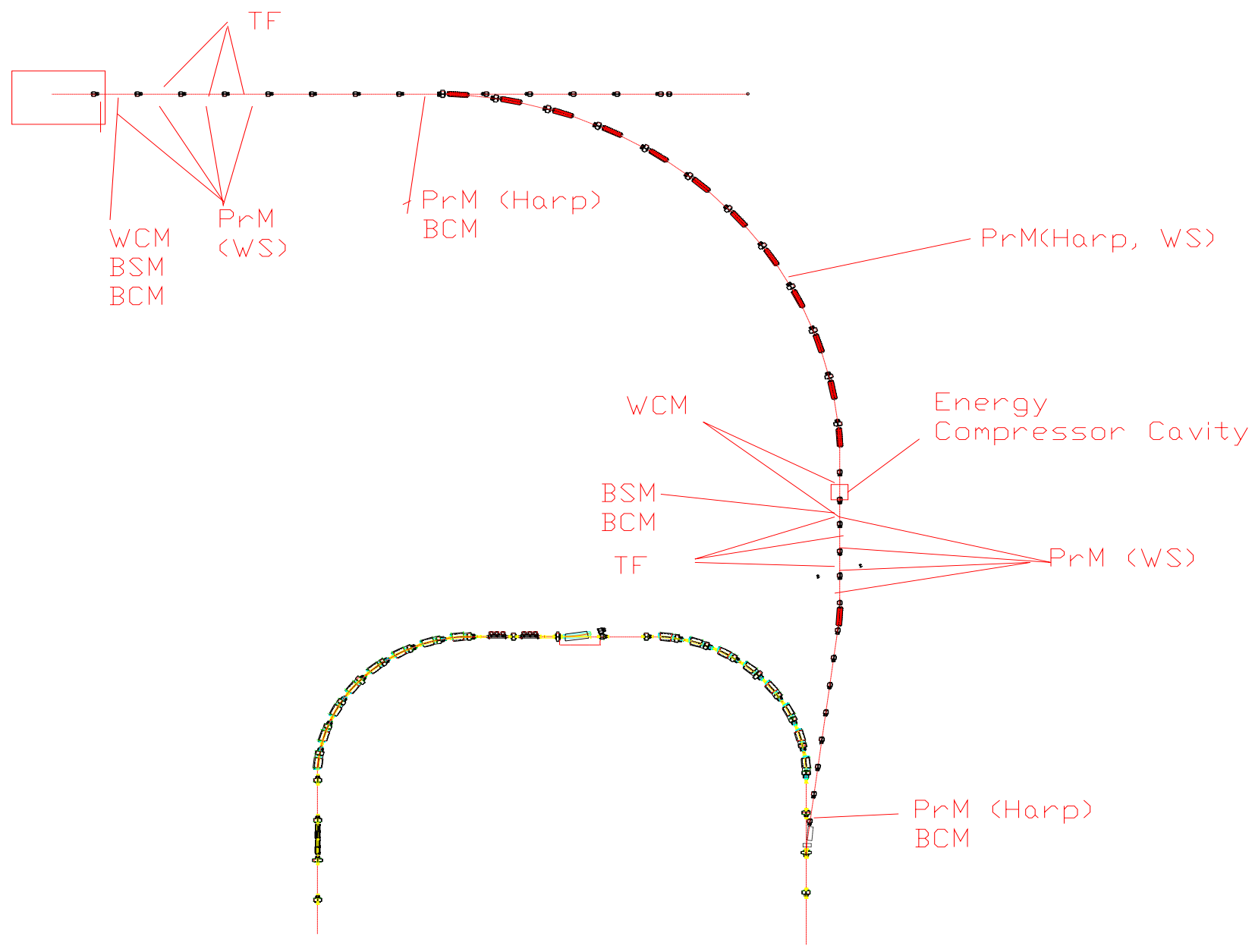

Figure 5: Schematic showing the location of the diagnostics in the HEBT line. 


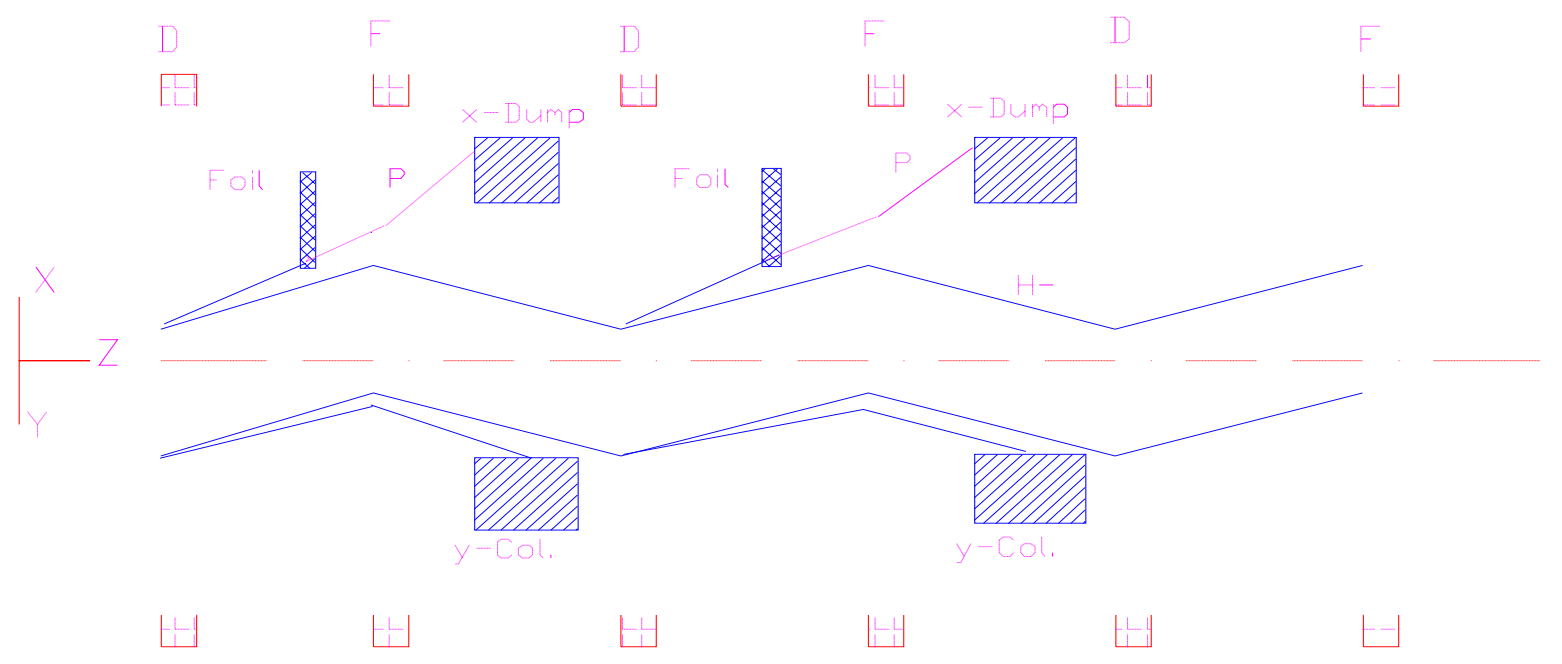

Figure 6: Schematic of the HEBT collimator configuration. 
Table 7: Apertures in the HEBT

$\begin{array}{lllllr}\text { Location } & \beta_{(\max )} & \begin{array}{l}\eta \\ (\mathrm{m})\end{array} & \begin{array}{l}\text { RMS Beam Size } \\ (\mathrm{mm})\end{array} & \begin{array}{l}\text { Available Aperture } \\ (\mathrm{mm})\end{array} & \text { Ratio } \\ \text { LAMS } & 23.5 & 0 & 3.6 & 110 & 27 \\ \text { Achromat } & 23.5 & 8.9 & 3.6,11.6(\mathrm{~V}, \mathrm{H}) & 70,180(\mathrm{~V}, \mathrm{H}) & 19,15 \\ \text { Energy Spreader } & 22.0 & 0 & 3.5 & 48 & 13 \\ \text { ARMS } & 15 & 1 & 2.8,7.3(\mathrm{~V}, \mathrm{H}) & 70,110(\mathrm{~V}, \mathrm{H}) & 15\end{array}$

Table 6 gives the locations and radii of the collimators.

Collimator locations are chosen such that they provide approximately full collimation of the transverse phase space. Figures 8 and 9 show the $\mathrm{x}$ and $\mathrm{y}$ phase space with collimators.

The apertures are kept more than 15 times the rms beam size everywhere in the line except in the energy spreader cavity. Table 7 gives the aperture sizes in the HEBT. Figure 10 shows the expected losses in the various HEBT sections as a function of emittance.

\subsection{Linac Dump}

In addition to the $90^{\circ}$ bend to the accumulator, there is a 35 meter long beam line straight out of the linac for linac characterization and beam dumping. Figure 11 shows the TRANSPORT calculation for the optics of this line.

\section{Space Charge and Momentum Spread}

The space charge effects are moderate in the line. The tune depression, defined by $\mu=\frac{\sigma}{\sigma_{0}}$, where $\sigma$ and $\sigma_{0}$ are the tune with and without the space charge, is only 0.87 . The Table 8 shows these values for different beam currents. The tune depression for $1 \mathrm{MW}$ and $2 \mathrm{MW}$ is the almost same, because for the 2 MW case the emittances are larger. The space charge effects become important in the achromat, where it induces dispersion which CANNOT be controlled by the usual "knobs", i.e. quadrupoles. When linear space charge is included in the calculation this system is no longer an achromat, even when the matrix elements R16 and R26 vanish at the end of the achromat section. The linear space charge in the presence of the bend provides coupling between (a) bunch width and bunch length (R15) and (b) bunch angular width and bunch length (R25).

This coupling is induced by linear space charge, which can be shown as 


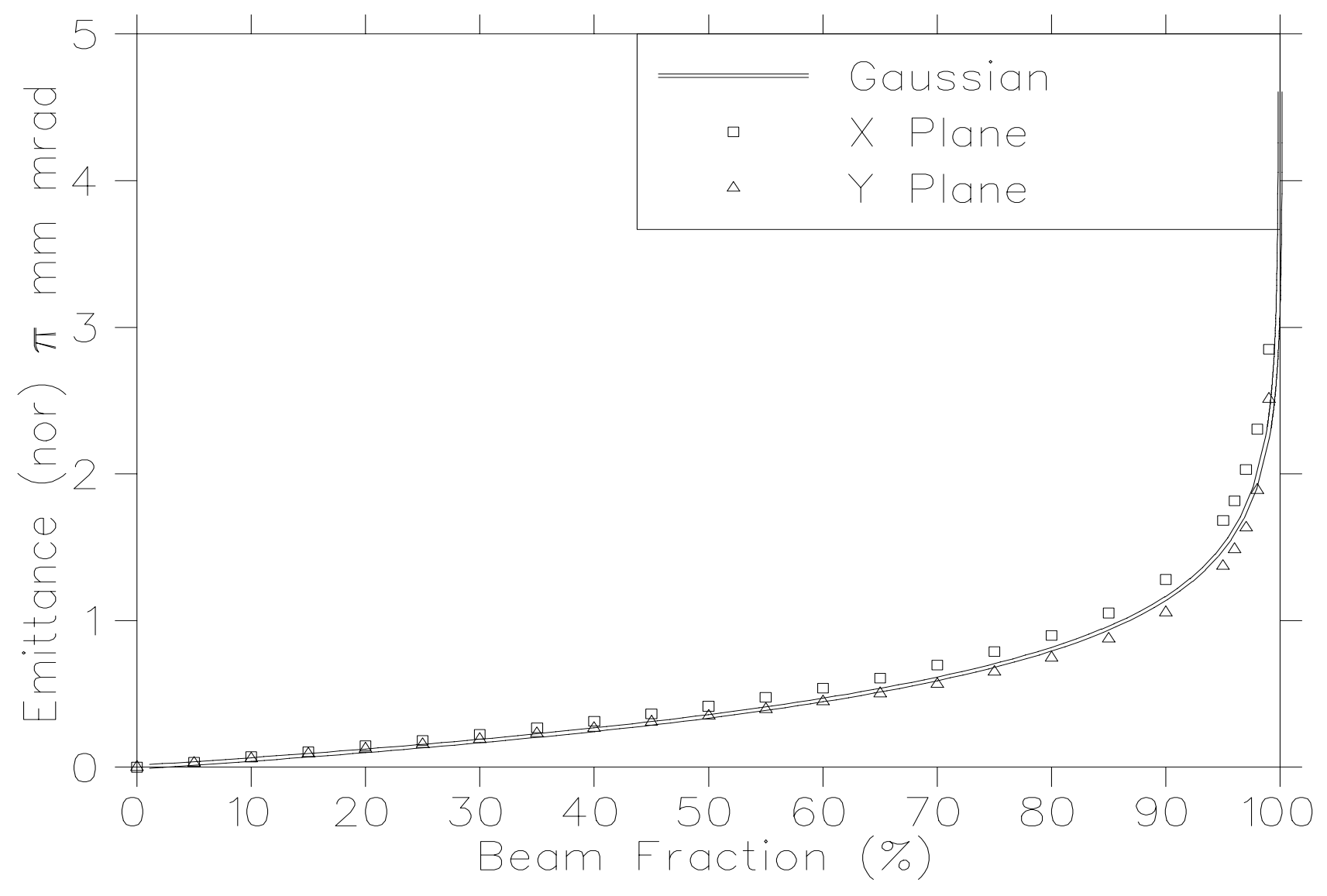

Figure 7: Emittance as a function of beam fraction for a Gaussian distribution and a particle distribution obtained from an end to end simulation at $1 \mathrm{MW}$. 


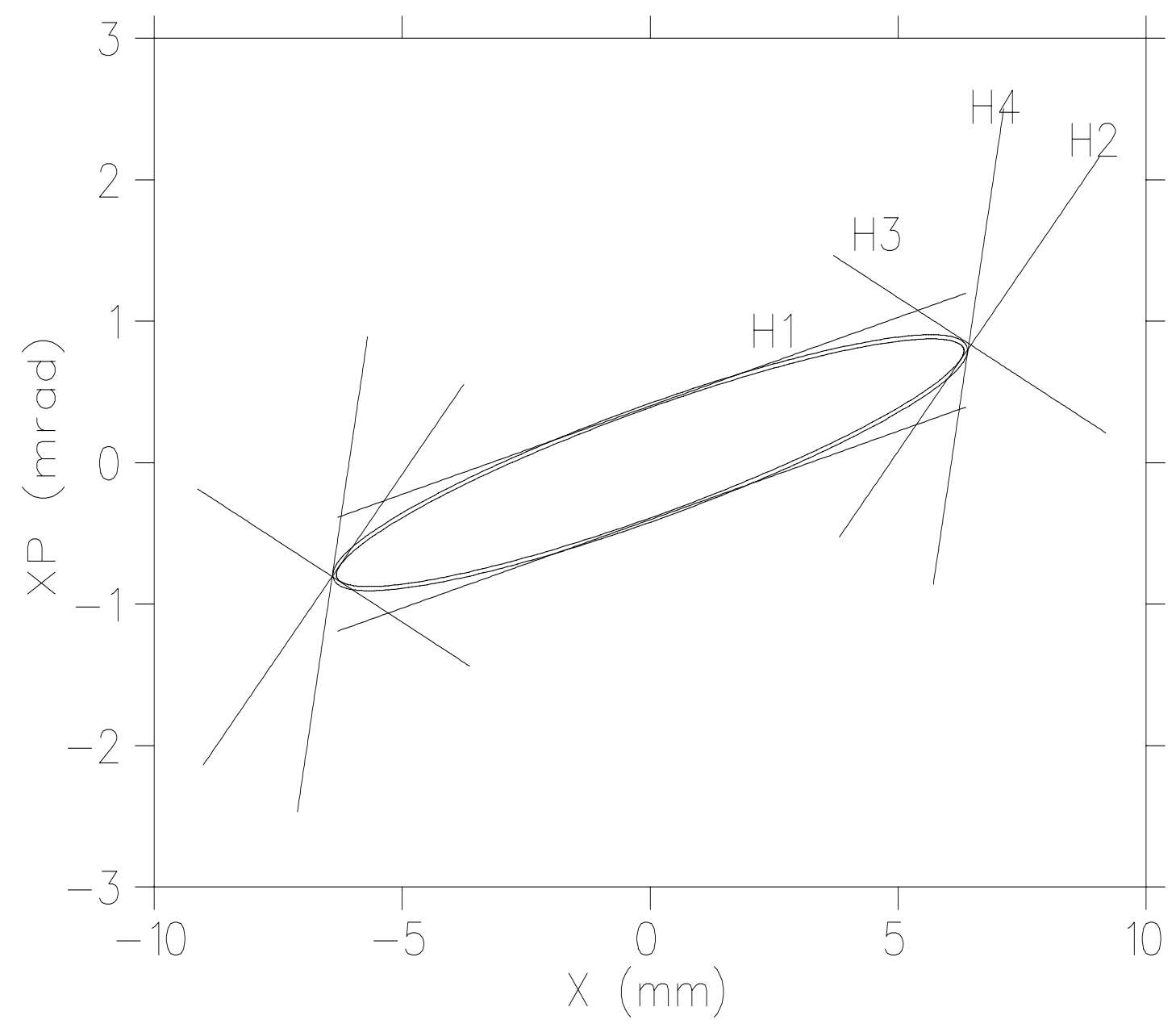

Figure 8: X-XP phase space at the foil with collimator projections for emittance $=18.4 \times \epsilon_{R M S}$. 


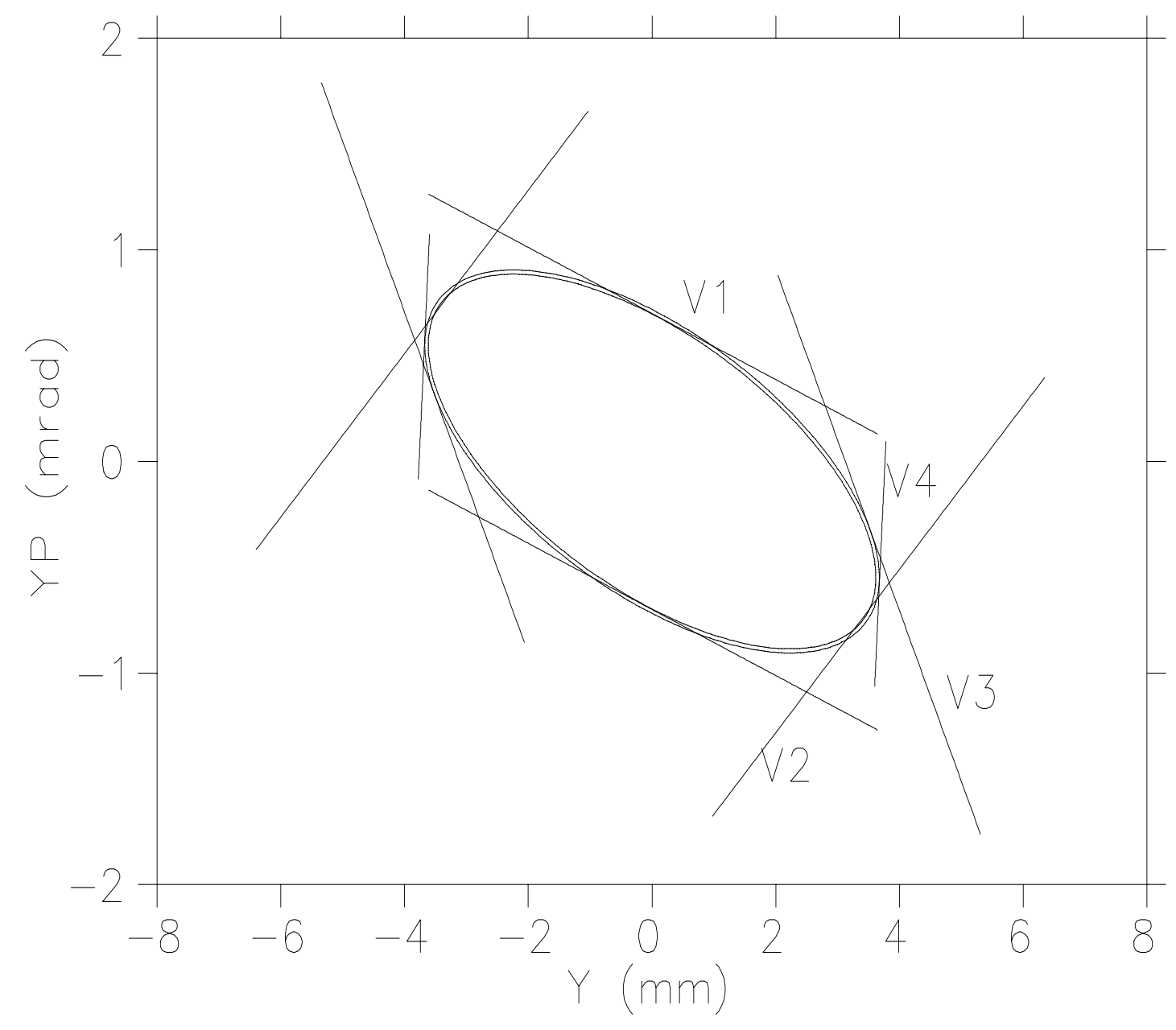

Figure 9: Y-YP phase space at the foil with collimator projections for emittance $=18.4 \times \epsilon_{R M S}$. 


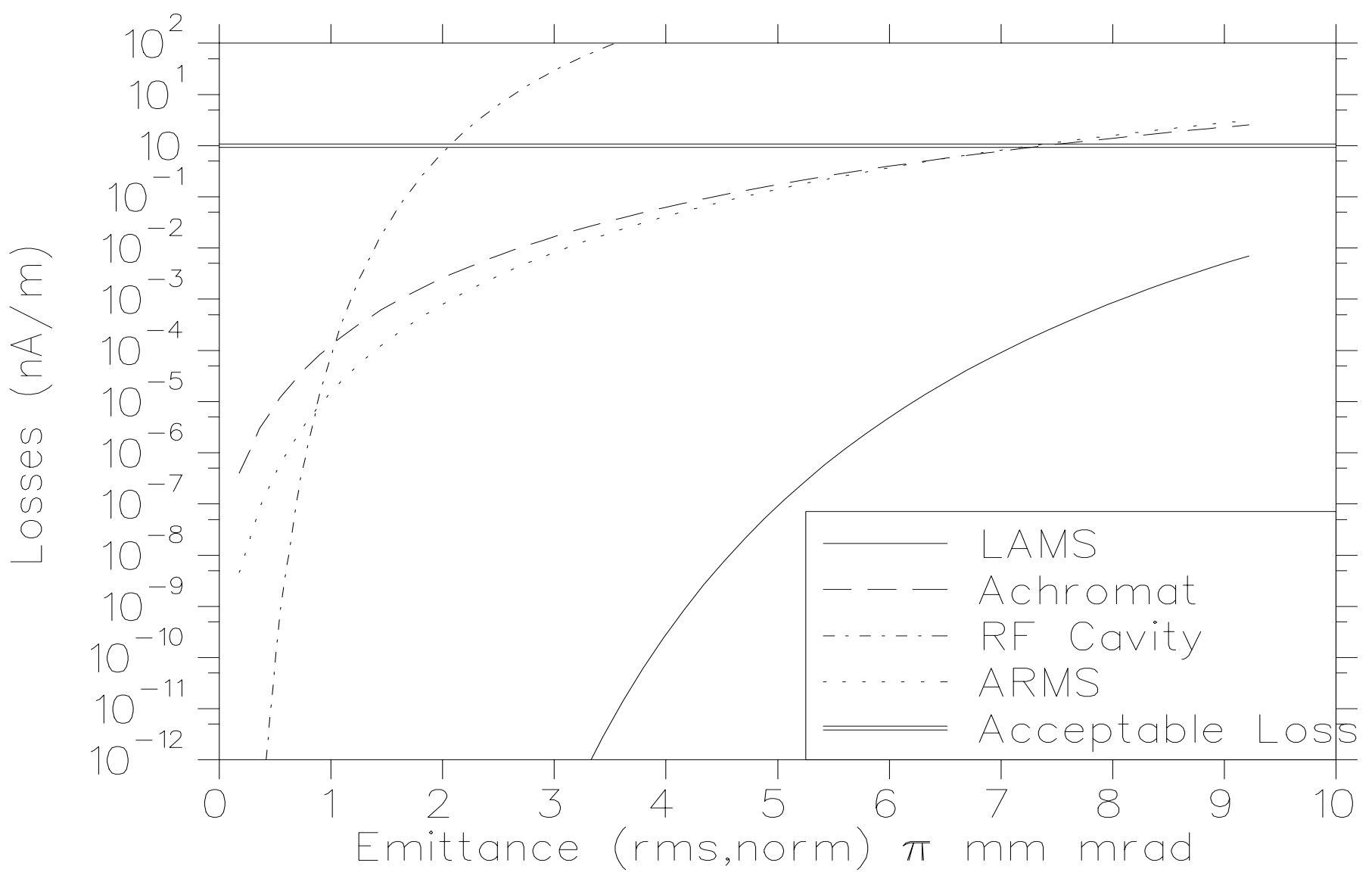

Figure 10: Beam losses as a function of emittance for LAMS, Achromat, ARMS and energy spreader cavity (RF cavity). 


\section{SNS LINAC DUMP LINE}

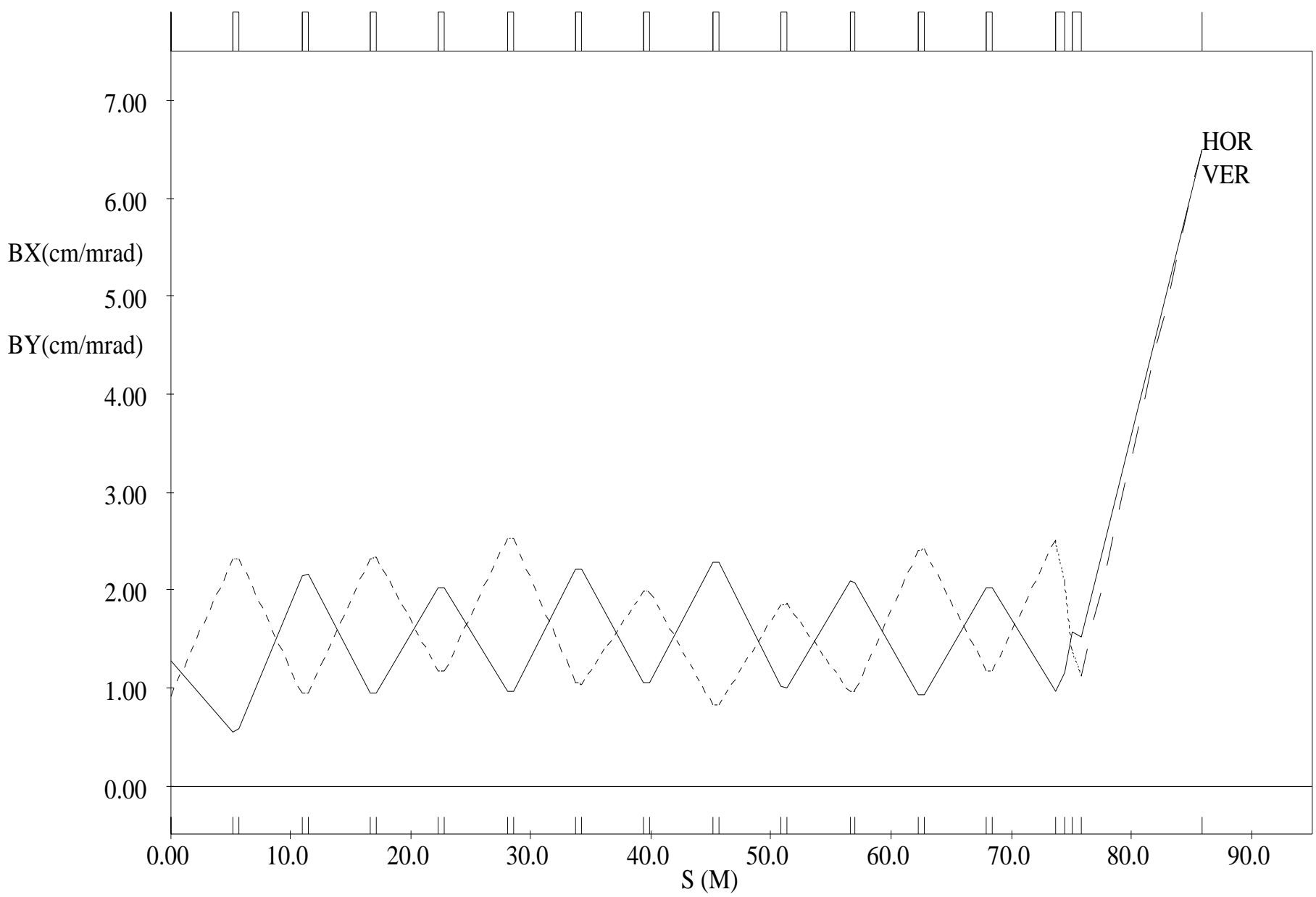

Figure 11: TRANSPORT calculation of the beam optics to the linac dump. 
Table 8: Tune Depression and Energy Spread

\begin{tabular}{|c|c|c|c|c|c|}
\hline $\begin{array}{l}\text { Current } \\
(\mathrm{mA})\end{array}$ & $\begin{array}{l}\sigma \\
(\operatorname{deg})\end{array}$ & $\begin{array}{l}\sigma_{0} \\
(\mathrm{deg})\end{array}$ & $\mu$ & $\begin{array}{l}\Delta E \\
@ \text { Entrance } \\
(\mathrm{MeV})\end{array}$ & $\begin{array}{l}\Delta E \\
@ \text { Foil }^{\S} \\
(\mathrm{MeV})\end{array}$ \\
\hline 0 & 60 & 60 & 1.00 & 1.063 & 1.063 \\
\hline 56 & 52 & 60 & 0.87 & 1.063 & 1.895 \\
\hline 122 & 51 & 60 & 0.85 & 1.388 & 2.400 \\
\hline
\end{tabular}

follows. Following the formalism of TRACE3D [5], the electric field components due to a uniformly charged ellipsoid are given by [6]

$$
\begin{gathered}
E_{x}=\frac{1}{4 \pi \epsilon_{0}} \frac{3 I \lambda}{c \gamma^{2}} \frac{(1-f)}{r_{x}\left(r_{x}+r_{y}\right) r_{z}} x, \\
E_{y}=\frac{1}{4 \pi \epsilon_{0}} \frac{3 I \lambda}{c \gamma^{2}} \frac{(1-f)}{r_{y}\left(r_{x}+r_{y}\right) r_{z}} y, \\
E_{z}=\frac{1}{4 \pi \epsilon_{0}} \frac{3 I \lambda}{c} \frac{f}{r_{x} r_{y} r_{z}} z,
\end{gathered}
$$

where $r_{x}, r_{y}$ and $r_{z}$ are the semi-axes of a ellipsoid, I is the average electrical current over one RF period, $\lambda$ is the free-space wavelength of the RF, $c$ is the velocity of light, and $\epsilon_{0}$ is the permittivity of the free space. The form factor $f$ is a function of $p \equiv \frac{\gamma r_{z}}{\sqrt{r_{x} r_{y}}}$, given by

$$
f(p)= \begin{cases}\frac{1}{1-p^{2}}-\frac{p}{(1-p)^{3 / 2}} \cos ^{-1} p & \text { if } p<1 \\ \frac{p \cosh ^{-1} p}{\left(p^{2}-1\right)^{3 / 2}}-\frac{1}{\left(p^{2}-1\right)} & \text { if } p>1 \\ \frac{1}{3} & \text { if } p=1\end{cases}
$$

where $\cosh ^{-1} p=\ln \left(p+\sqrt{p^{2}-1}\right)$.

The space charge is applied in the kick approximation as a change in the normalized momentum components as the beam traverses $\Delta \mathrm{s}$, and is given by

$$
\Delta(\beta \gamma)_{u}=\frac{q E_{u} \Delta s}{m_{0} c^{2} \beta}
$$

where $\mathrm{u}$ represents $\mathrm{x}, \mathrm{y}$, or $\mathrm{z}$. This kick formulation is correct as long as the ellipsoid is upright in local $x-y, y-z$, and $z-x$ planes. When beam traverses the 
bend the ellipsoid is tilted in the local $\mathrm{x}-\mathrm{z}$ plane. To calculate the space charge kick first one has to transform to the coordinate system in which the ellipsoid is upright. The ellipsoid is transformed back to the local coordinate system after applying the space charge kick. The transfer matrix for the space-charge kick is

$$
R_{S}=\left(\begin{array}{llllll}
1 & 0 & 0 & 0 & 0 & 0 \\
\frac{q E_{x} \Delta s}{m_{0} c^{2} \beta} & 1 & 0 & 0 & 0 & \\
0 & 0 & 1 & 0 & 0 & 0 \\
0 & 0 & \frac{q E_{y} \Delta s}{m_{0} c^{2} \beta} & 1 & 0 & 0 \\
0 & 0 & 0 & 0 & 1 & 0 \\
0 & 0 & 0 & 0 & \frac{q E_{z} \Delta s}{m_{0} c^{2} \beta} & 1
\end{array}\right) .
$$

The transfer matrix of a bending magnet for bend angle $\alpha$ and length $\mathrm{L}$ is

$$
R_{B}=\left(\begin{array}{llllll}
\cos \left(k_{x} L\right) & \frac{1}{k_{x}} \sin \left(k_{x} L\right) & 0 & 0 & 0 & \frac{h\left(1-\cos \left(k_{x} L\right)\right)}{k_{x}^{2}} \\
-k_{x} \sin \left(k_{x} L\right) & \cos \left(k_{x} L\right) & 0 & 0 & 0 & \frac{h \sin \left(k_{x}^{2} L\right)}{k_{x}} \\
0 & 0 & \cos \left(k_{y} L\right) & \frac{1}{k_{y}} \sin \left(k_{y} L\right) & 0 & 0 \\
0 & 0 & -k_{y} \sin \left(k_{y} L\right) & \cos \left(k_{y} L\right) & 0 & 0 \\
\frac{-h \sin \left(k_{x} L\right)}{k_{x}} & \frac{-h\left(1-\cos \left(k_{x} L\right)\right)}{k_{x}^{2}} & 0 & 0 & 1 & \frac{-1}{\rho^{2} k_{x}^{3}}\left(k_{x} L \beta^{2}\right. \\
& & & & & \left.-\sin \left(k_{x} L\right)\right) \\
0 & 0 & 0 & 0 & 0 & 1
\end{array}\right)
$$

where

$$
\begin{gathered}
h=\frac{1}{|\rho|} \frac{\alpha}{|\alpha|} \\
k_{x}=\sqrt{(1-n) h^{2}} \\
k_{y}=\sqrt{n h^{2}} \\
L=|\rho| \alpha \\
\rho=\frac{m_{0} c \beta \gamma}{q B_{y}} \\
n=-\left(\frac{\rho}{B_{y}} \frac{\partial B_{y}}{\partial x}\right)_{x=0, y=0}
\end{gathered}
$$

When space-charge is included in the calculation for the bending magnet in the kick approximation, the two matrices $\mathrm{R}_{S}$ and $\mathrm{R}_{B}$ are multiplied, and the resultant matrix $R_{S B}$ will have $R_{S B} 15$ and $R_{S B} 25$ non-zero and given by

$$
\begin{gathered}
R_{S B} 15=R_{B} 16 * R_{S} 65=\frac{h\left(1-\cos \left(k_{x} L\right)\right)}{k_{x}^{2}} \times \frac{q E_{z} L}{m_{0} c^{2} \beta} \\
R_{S B} 25=R_{B} 26 * R_{S} 65=\frac{h \sin \left(k_{x}\right) L}{k_{x}} \times \frac{q E_{z} L}{m_{0} c^{2} \beta} .
\end{gathered}
$$


Even after applying the usual conditions for an achromat, R16=R26=0, the system is not achromatic. To completely remove coupling between $\mathrm{x}-\mathrm{x}$ ' and $\mathrm{z}-\mathrm{z}$ ' planes, not only the determinant of sub-matrix $\mathrm{R}[\mathrm{xz}]$ has to be zero, but all of its elements have to be zero. If any element of this sub-matrix is non-zero, it means that beam is not upright in the $\mathrm{x}-\mathrm{z}$ plane. The coupling provided by the space charge will effectively produce dispersion (R16), angular dispersion (R26) and non-zero matrix elements R15 \& R25. The beam ellipse can be made upright in $\mathrm{X}-\mathrm{z}$ plane by introducing two rf cavities in the achromat.

The angle between the $\mathrm{z}$-axis and the axis of the elliptical projection on the $\mathrm{z}$ - $\mathrm{X}$ plane is as follows

$$
\theta=\frac{1}{2} \tan ^{-1} \frac{2 \sigma_{51}}{\sigma_{55}-\sigma_{11}}
$$

The ellipsoid is be brought upright to the $\mathrm{z}-\mathrm{x}$ plane by a rotation of $-\theta$ accomplished by applying the following transfer matrix

$$
\left(\begin{array}{llllll}
C & 0 & 0 & 0 & -S & 0 \\
0 & C & 0 & 0 & 0 & -S \\
0 & 0 & 0 & 0 & 0 & 0 \\
0 & 0 & 0 & 0 & 0 & 0 \\
S & 0 & 0 & 0 & C & 0 \\
0 & S & 0 & 0 & 0 & C
\end{array}\right)
$$

where $\mathrm{C}$ and $\mathrm{S}$ denote $\cos \theta$ and $\sin \theta$. and then applying the space charge kick given by matrix $R_{S}$ and then rotating back by $\theta$ to local coordinate system. The transfer matrix of the achromat in the HEBT for the zero current (using TRACE3D ) is

$$
R_{\text {acro }}=\left(\begin{array}{llllll}
1 & 0 & 0 & 0 & 0 & 0 \\
0 & 1 & 0 & 0 & 0 & 0 \\
0 & 0 & 1 & -1.305 & 0 & 0 \\
0 & 0 & 0.01778 & 0.98846 & 0 & 0 \\
0 & 0 & 0 & 0 & 1 & 14.15989 \\
0 & 0 & 0 & 0 & 0 & 1
\end{array}\right)
$$

with the following units

$$
\left(\begin{array}{llllll}
1 & m & 1 & m & 1 & m \\
m^{-1} & 1 & m^{-1} & 1 & m^{-1} & 1 \\
1 & m & 1 & m & 1 & m \\
m^{-1} & 1 & m^{-1} & 1 & m^{-1} & 1 \\
1 & m & 1 & m & 1 & m \\
m^{-1} & 1 & m^{-1} & 1 & m^{-1} & 1
\end{array}\right)
$$

The $\mathrm{R}[\mathrm{xz}]$ sub-matrix ofthe achromat plus the following two cells, for zero current, is 


$$
R[x z]_{\text {acro }+2 c}=\left(\begin{array}{cc}
0 & 0 \\
0 & 0
\end{array}\right)
$$

The $\mathrm{R}[\mathrm{xz}]$ sub-matrix for the achromat, with $28 \mathrm{~mA}$ current, is

$$
R[x z]_{\text {acro }}=\left(\begin{array}{ll}
0.133349 & -0.18495 \\
0.00469 & 0.8130
\end{array}\right)
$$

Now one can apply the conditions R $16=\mathrm{R} 26=0$, by adjusting two families of quadrupoles in the achromat, and the resultant $\mathrm{R}[\mathrm{xz}]$ sub-matrix of the achromat is

$$
R[x z]_{\text {acro }}=\left(\begin{array}{cc}
0.14278 & 0 \\
0.00339 & 0
\end{array}\right)
$$

The $\mathrm{R}[\mathrm{xz}]$ sub-matrix of the achromat plus the following two cells, for the 28 $\mathrm{mA}$, is then

$$
R[x z]_{a c r o+2 c}=\left(\begin{array}{ll}
-0.00608 & -0.68454 \\
-0.01605 & 0.01919
\end{array}\right)
$$

This shows the condition R16 $=\mathrm{R} 26=0$, will not yield a achromatic system if one includes space charge.

Next, one can apply the conditions R16 $=\mathrm{R} 26=\mathrm{R} 15=\mathrm{R} 25=0$ (instead of R16 = R26 =0) by adjusting the two families of quadrupoles in the achromat, and adding two small 1 meter RF cavities in the 2nd and 5th cells of the achromat set at appropriate voltages. One can then get the following $\mathrm{R}[\mathrm{xz}]$ sub-matrix, similar to the zero current case.

$$
R[x z]_{\text {acro }}=\left(\begin{array}{ll}
0 & 0 \\
0 & 0
\end{array}\right)
$$

For this case, however, the $\mathrm{R}[\mathrm{xz}]$ sub-matrix for the achromat plus the following two cells, for $28 \mathrm{~mA}$, is

$$
R[x z]_{\text {acro+2c }}=\left(\begin{array}{ll}
0 & 0 \\
0 & 0
\end{array}\right)
$$

Therefore, achromaticity should be redefined as a line having zero values of matrix elements R15, R25, R16 and R26. The additional condition can be achieved with two small $\mathrm{rf}$ cavities.

The space charge effect becomes stronger for the short bunch, so another way to reduce this effect is to increase the bunch length. Figure 12 shows the space charge induced dispersion as a function of bunch length for the HEBT. This plot was obtained as follows. First, the R16, R26 were made zero for zero current. Then the initial bunch length was changed while keeping the longitudinal emittance constant and including the space charge for $28 \mathrm{~mA}$ (one MW case). R16 was then calculated for each bunch length, using ????. 


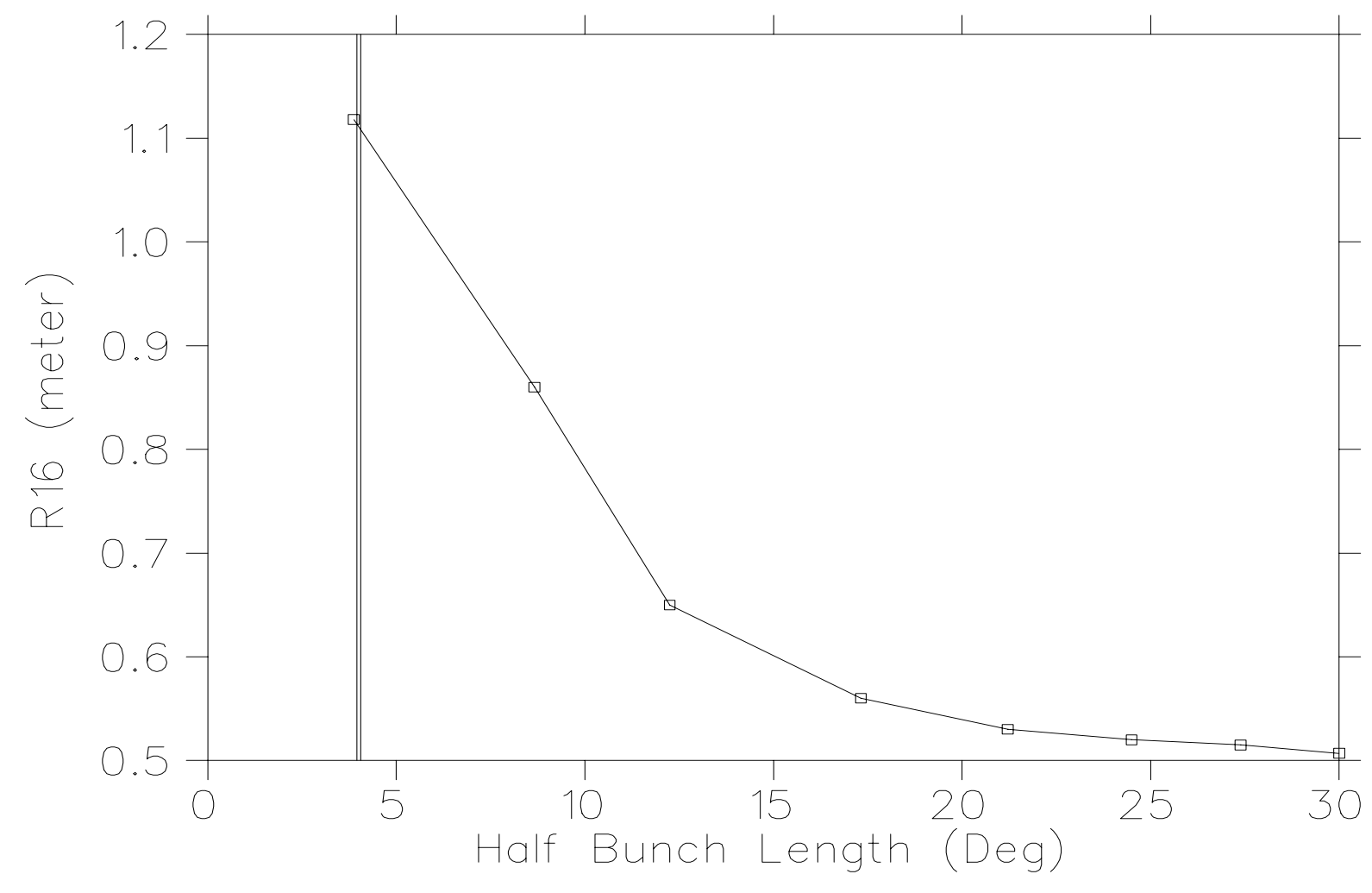

Figure 12: Space-charge induced dispersion (R16) as a function of the bunch length at the beginning of HEBT. 
Table 9: Alignment tolerances for the HEBT magnets

$\begin{array}{ll}\text { Type of Error } & \text { Tolerance } \\ \text { Translation (x and y) } & \pm 0.25 \mathrm{~mm} \\ \text { Pitch and yaw } & \pm 1 \mathrm{mrad} \\ \text { Rotation } & \pm 1.0 \mathrm{deg}\end{array}$

\section{Tolerances}

This machine must have very low beam losses, and therefore requires carefully chosen tolerances. The most harmful error to the emittance in the linac and transfer line is quadrupole rotation error. The linac and transfer line are not built with rotation corrective elements in it. That is, for $\mathrm{x}, \mathrm{y}$ misalignments the transfer line has corrective steering magnets along the transfer line but, unlike circular machines, there are no skew quadrupoles as corrective elements for the quadrupole rotation error. If the error becomes excessive, a properly arranged skew quadrupoles could be added.

The HEBT consists of quadrupoles and dipoles, and a buncher cavity. The emittance growth due to dipole field and alignment errors is given by

$$
\epsilon_{2}=\epsilon_{1}+\frac{\pi}{2}\left[(\Delta y)^{2} \frac{\left(1+\alpha^{2}\right)}{\beta}+\left(\Delta y^{\prime}\right)^{2} \beta\right]
$$

where $\Delta y$ is a magnet alignment error and $\Delta y^{\prime}=\frac{l \Delta B}{B \rho}$ an angle error from a field error $\Delta B$ of length l. The gradient errors in the quadrupole give following emitance:

$$
\epsilon_{2}=\frac{1}{2}\left(k^{2} \beta^{2}+2\right) \epsilon_{1}
$$

where $k=\frac{-l \Delta G}{B \rho}$ is an amplitude-dependent kick due to a gradient error $\Delta G$ of length 1 .

The quadrupole misalignments can be simulated by PARTRACE.

Figures 13 through 17 show the probability distribution of the beam centroid( figure 13), radius (figures 14 and 15) and emittance (figures 16 and 17) for various quadrupole alignment errors.

\section{Simulations}

We have used following programs to simulate HEBT (a) TRANSPORT, (b) TRACE3D, (c) PARMILA, and (d) PARTRACE.

TRANSPORT code is used to design the line to satisfy certain conditions to be fullfilled by the beam. This code does not include the space charge effects. 


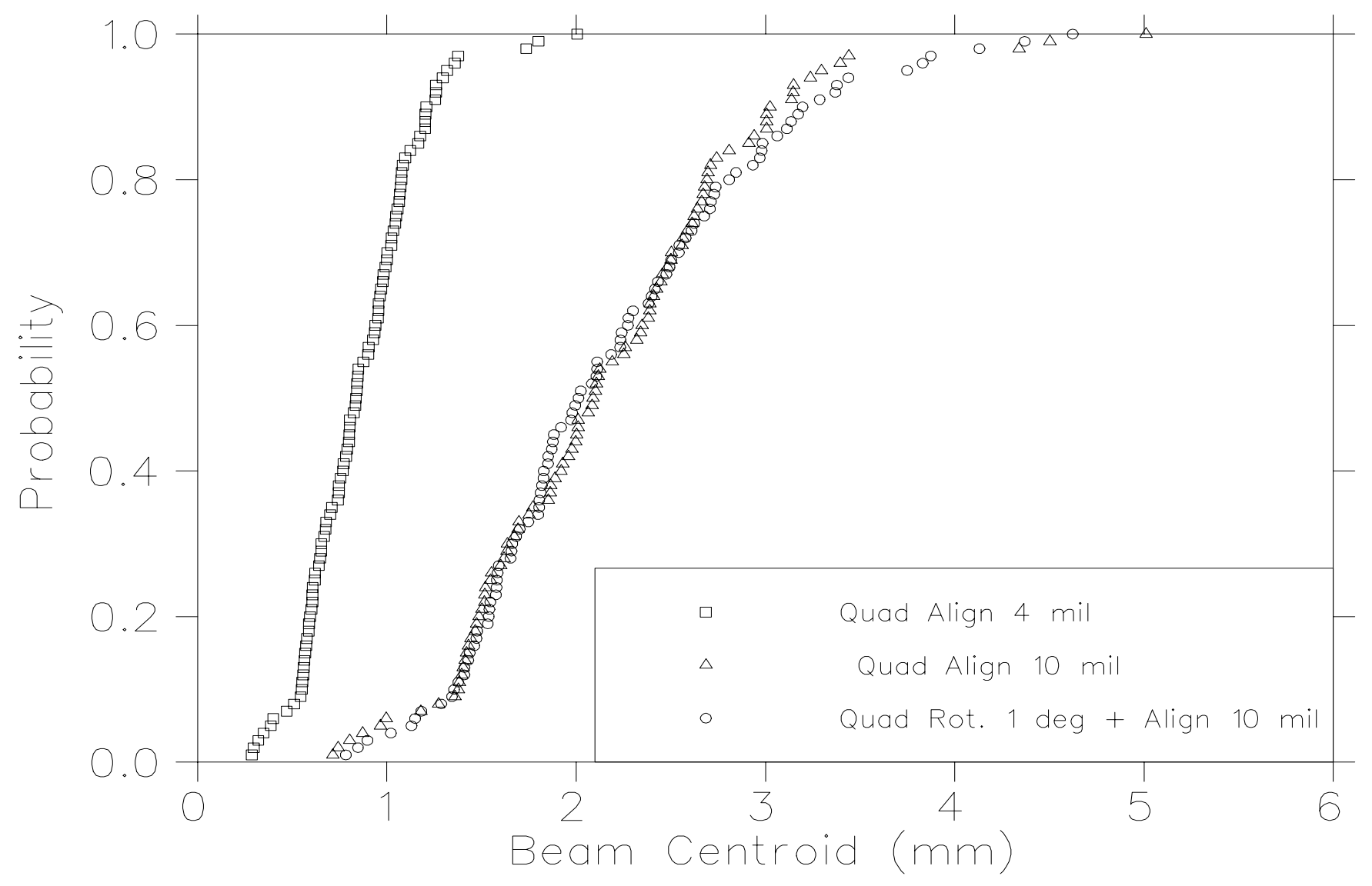

Figure 13: The probability distribution of maximum beam centroids for various quadrupole alignment errors. 


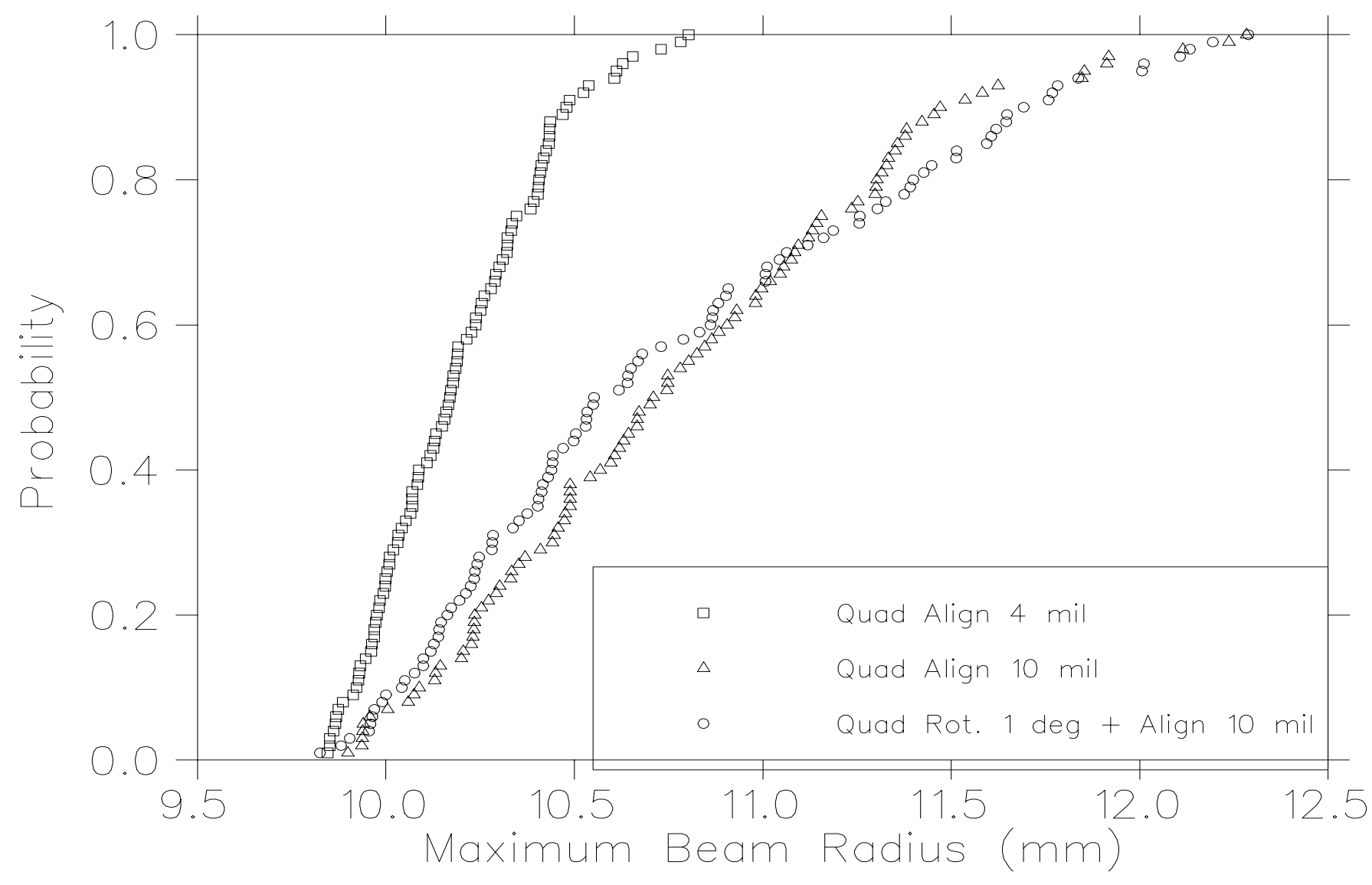

Figure 14: The probability distribution of maximum beam radius for various quadrupole alignment errors. 


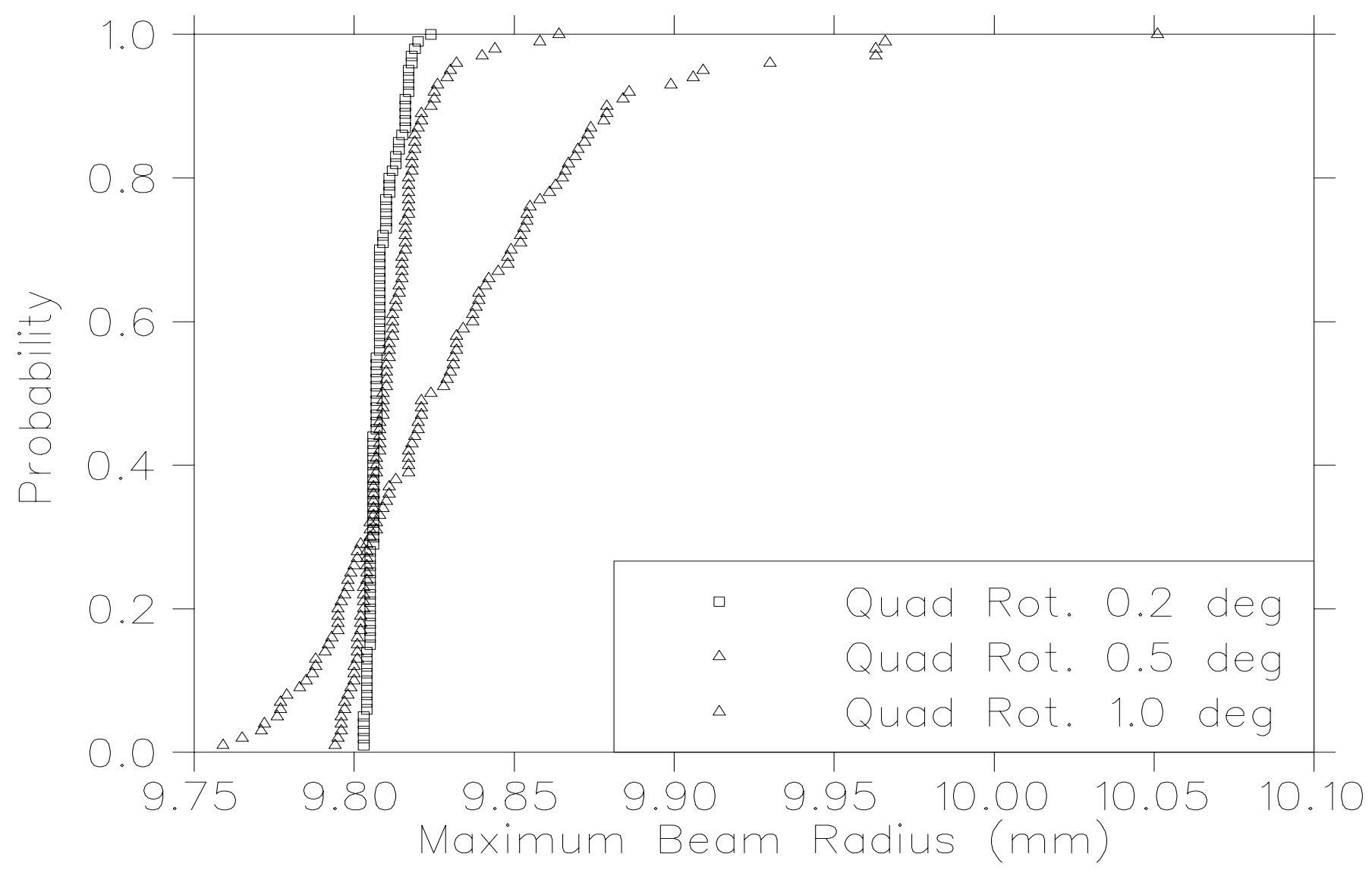

Figure 15: The probability distribution of maximum beam radius for various quadrupole rotation errors. 


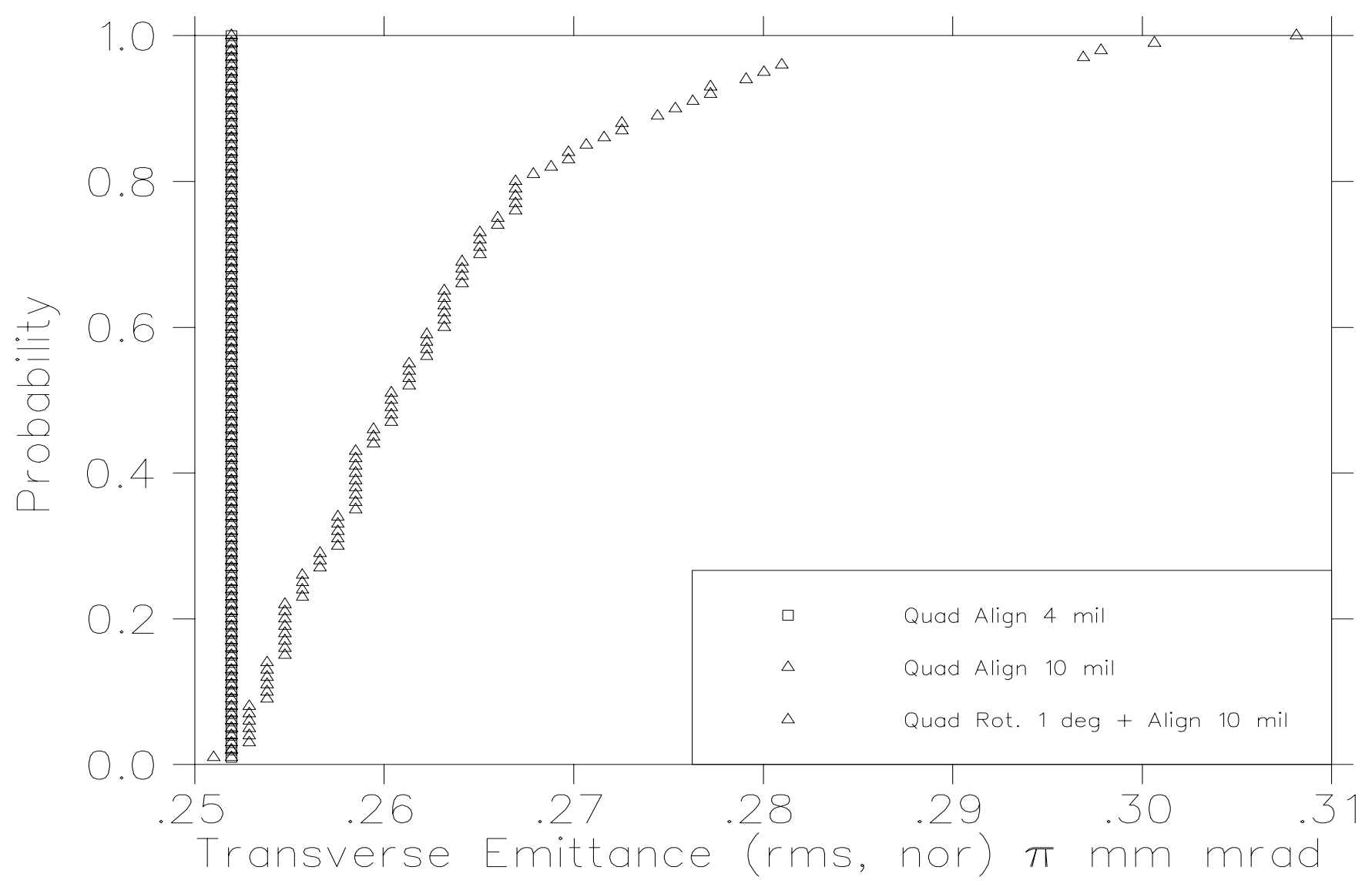

Figure 16: The probability distribution of transverse emittance for various quadrupole alignment errors. 


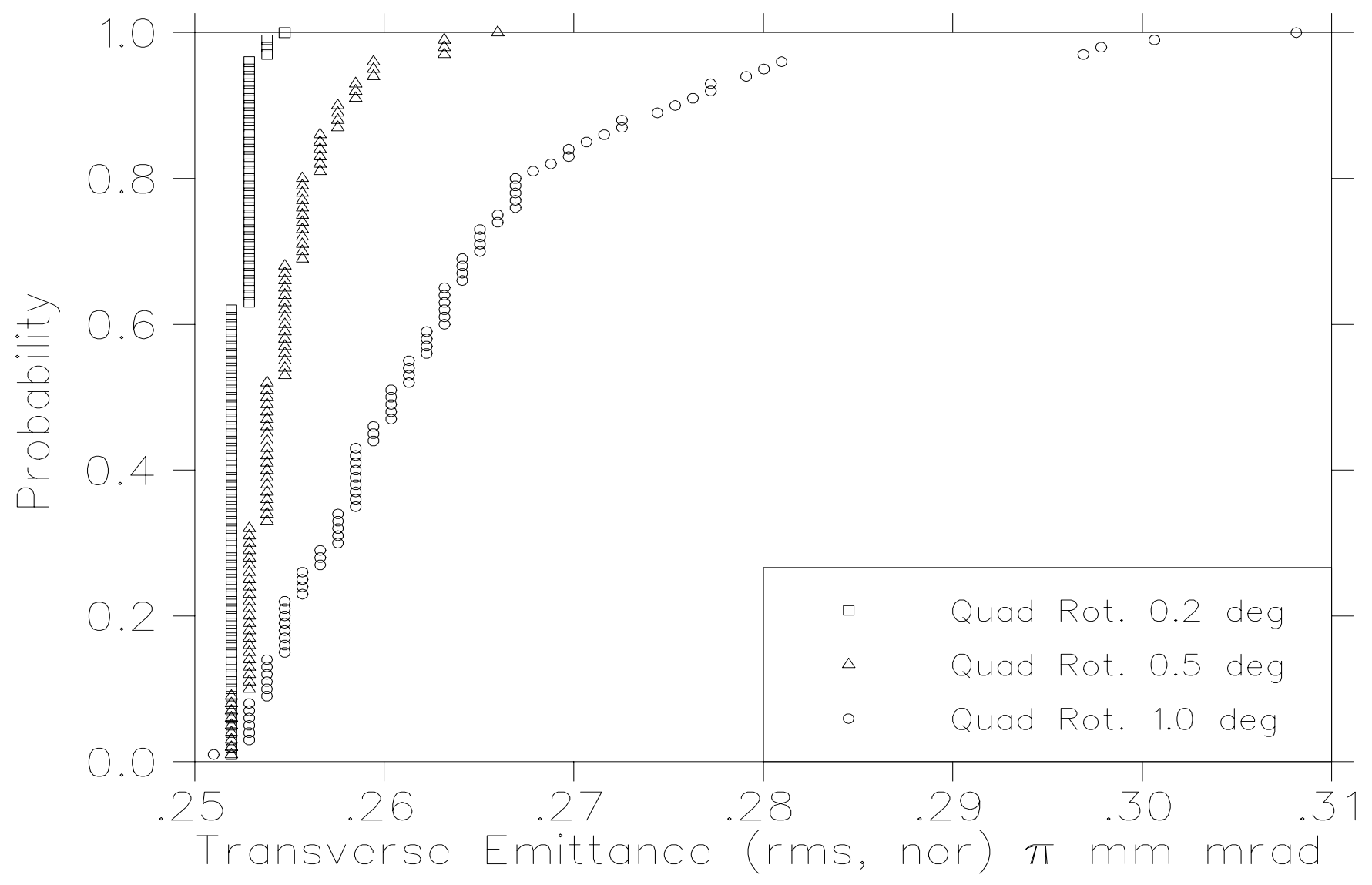

Figure 17: The probability distribution of transverse emittance for various quadrupole rotational errors. 
Table 10: Normalized RMS emittance at the foil for different starting conditions.

$\begin{array}{ccccc}\begin{array}{c}\text { Starting } \\ \text { at }\end{array} & \text { Beam Power } & \begin{array}{c}\epsilon_{x} \\ \pi \mathrm{mm} \text { mrad }\end{array} & \begin{array}{c}\epsilon_{y} \\ \pi \mathrm{mm} \mathrm{mrad}\end{array} & \begin{array}{c}\epsilon_{y} \\ \pi \mathrm{MeV} \text { deg }\end{array} \\ \text { DTL } & 1 \mathrm{MW} & 0.208 & 0.213 & 0.218 \\ \text { RFQ } & 1 \mathrm{MW} & 0.252 & 0.248 & 0.301 \\ \text { DTL } & 2 \mathrm{MW} & 0.197 & 0.211 & 0.251 \\ \text { RFQ } & 2 \mathrm{MW} & 0.320 & 0.330 & 0.440\end{array}$

This simulation starts at the beginning of the HEBT and finishes at the stripper foil.

TRACE3D is used to optimized the lattice with certain configurations of the RF cavity. It does include the space charge effects in the linear approximation. This simulation starts from the 2 nd to last cavity of the linac and finishes at the foil.

PARMILA is used to simulate the line with full space charge. We have used the transport line option of PARMILA to simulate HEBT.

PARTRACE is used to estimate the effects of quadrupole alignment errors. The code generates 100 different lines with random errors in the quadrupoles, calculates the beam parameters in the each case, and then arranges each beam parameter in the ascending order.

\subsection{End-To-End Simulation}

These simulation have been carreid out in collaboration with LANL. So far we have done four end-to-end simulations: (1) Starting at the DTL entrance at 2.5 $\mathrm{MeV}$ for $1 \mathrm{MW}$ beam (beam current $28 \mathrm{~mA}$ ), (2) starting at the RFQ entrance at $0.065 \mathrm{MeV}$ for $1 \mathrm{MW}$ beam (beam current $28 \mathrm{~mA}$ ), (3) Starting at the DTL entrance at $2.5 \mathrm{MeV}$ for $2 \mathrm{MW}$ beam (beam current $56 \mathrm{~mA}$ ), and (4) starting at the RFQ entrance at $0.065 \mathrm{MeV}$ for $2 \mathrm{MW}$ beam (beam current $56 \mathrm{~mA}$ ).

LANL personnel run PARMTEQ and PARMILA codes to carry the beam to the end of the CCDTL at $167 \mathrm{MeV}$, then pass the particle distribution to BNL, where these particles are carried from $167 \mathrm{MeV}$ to $1000 \mathrm{MeV}$, and then to the stripper foil at ring injection. Table 10 shows the Normalized RMS emittance for these four cases at the foil

There are sets of 3 figures for each of the above four cases: (1) the beam distribution at the start of the CCL at $167 \mathrm{MeV},(2)$ the beam distribution at the start of the HEBT, and (3) the beam distribution at the stripper foil.

One sees that the beam can be matched properly in all cases, but to date all these end-to-end simulations do not include errors. 


\section{References}

[1] W. T. Weng, et al, to be published in Proceedings of 1997 Particle Accelerator Conference, Vancouver, B.C. Canada, May 12-16, 1997.

[2] D. Raparia, J. Alessi, Y.Y. Lee, W. T. Weng, to be published in Proceedings of 1997 Particle Accelerator Conference, Vancouver, B.C. Canada, May 12$16,1997$.

[3] D. Raparia, J. Alessi, Y.Y. Lee, W. T. Weng, BNL/SNS Technical Note No 06, April 1997.

[4] H. Ludewig, A. Aronson, R. Blumberg, J. Walker, J. Brodowski, D. Raparia, M. Todosow, BNL/SNS Technical Note No 044, April 1998.

[5] K. R. Crandall and D. P. Rusthoi, Los Alamos Report LA-UR-97-886.

[6] P. M. Lapostolle, CERN report AR/Int. SG/65-15, Geneva, Switzerland, July 1965 . 

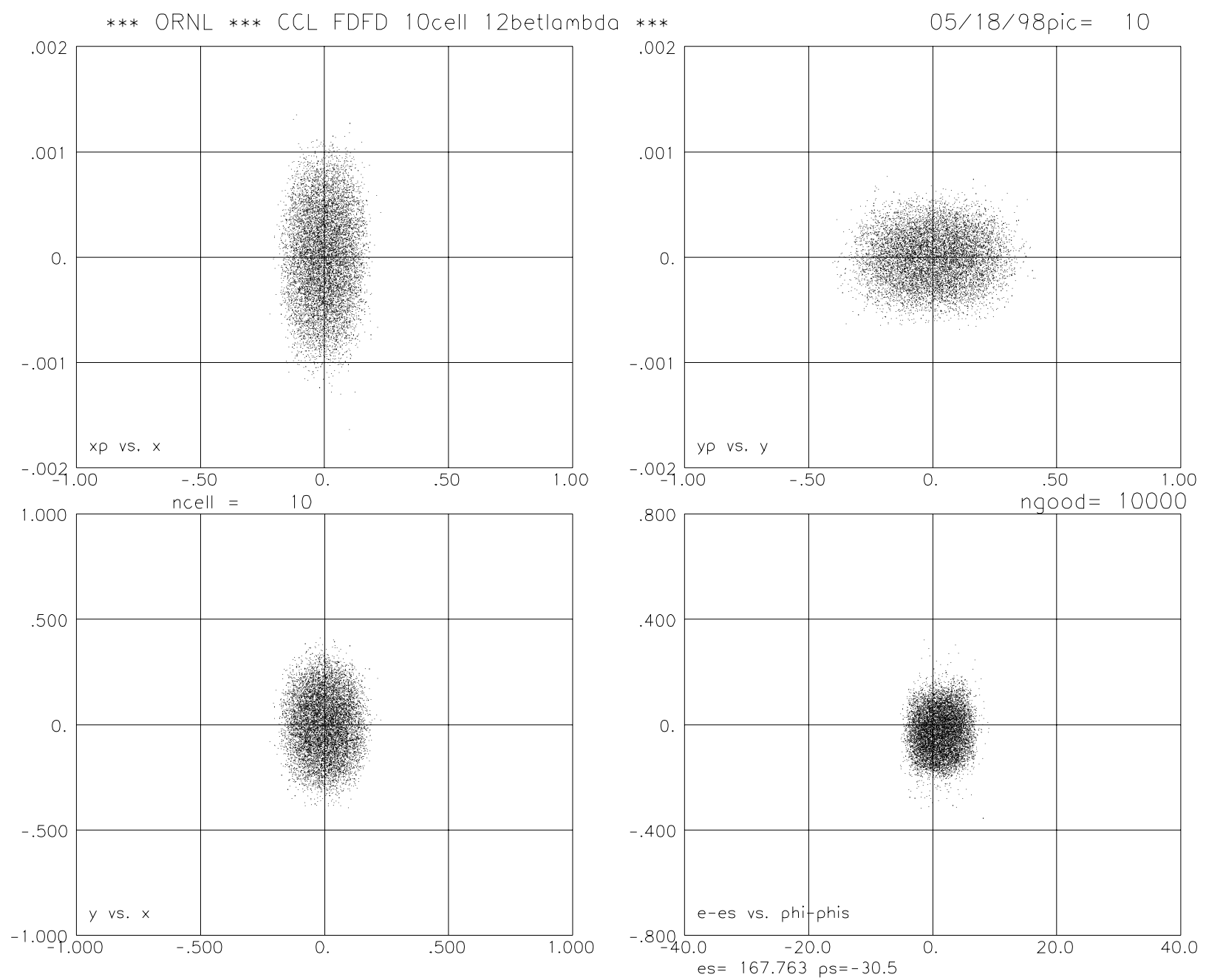

Figure 18: Beam distribution at the beginning of the CCL, starting at the DTL, for 1 MW. 


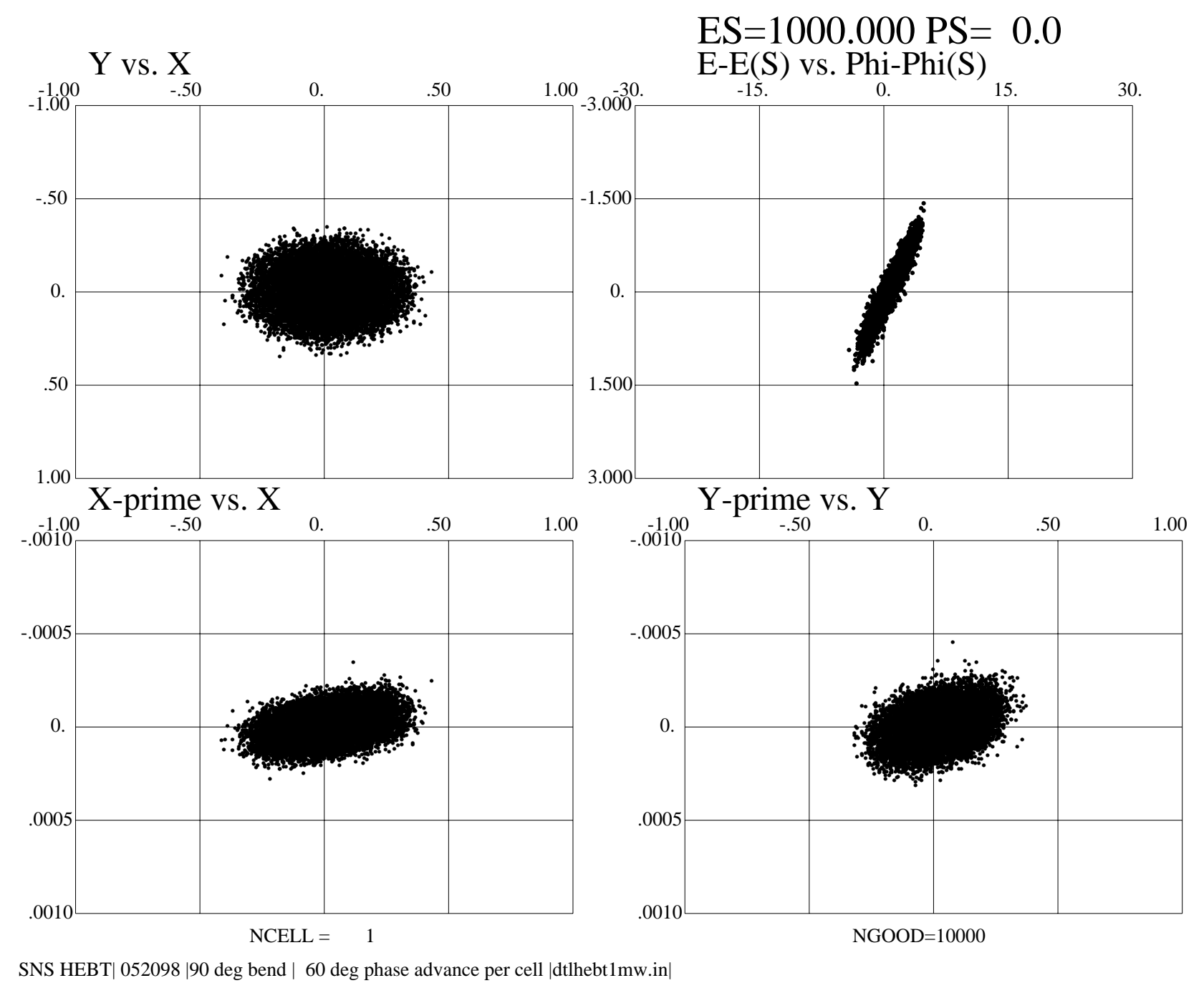

Figure 19: Beam distribution at the beginning of the HEBT, starting at the DTL, for $1 \mathrm{MW}$. 


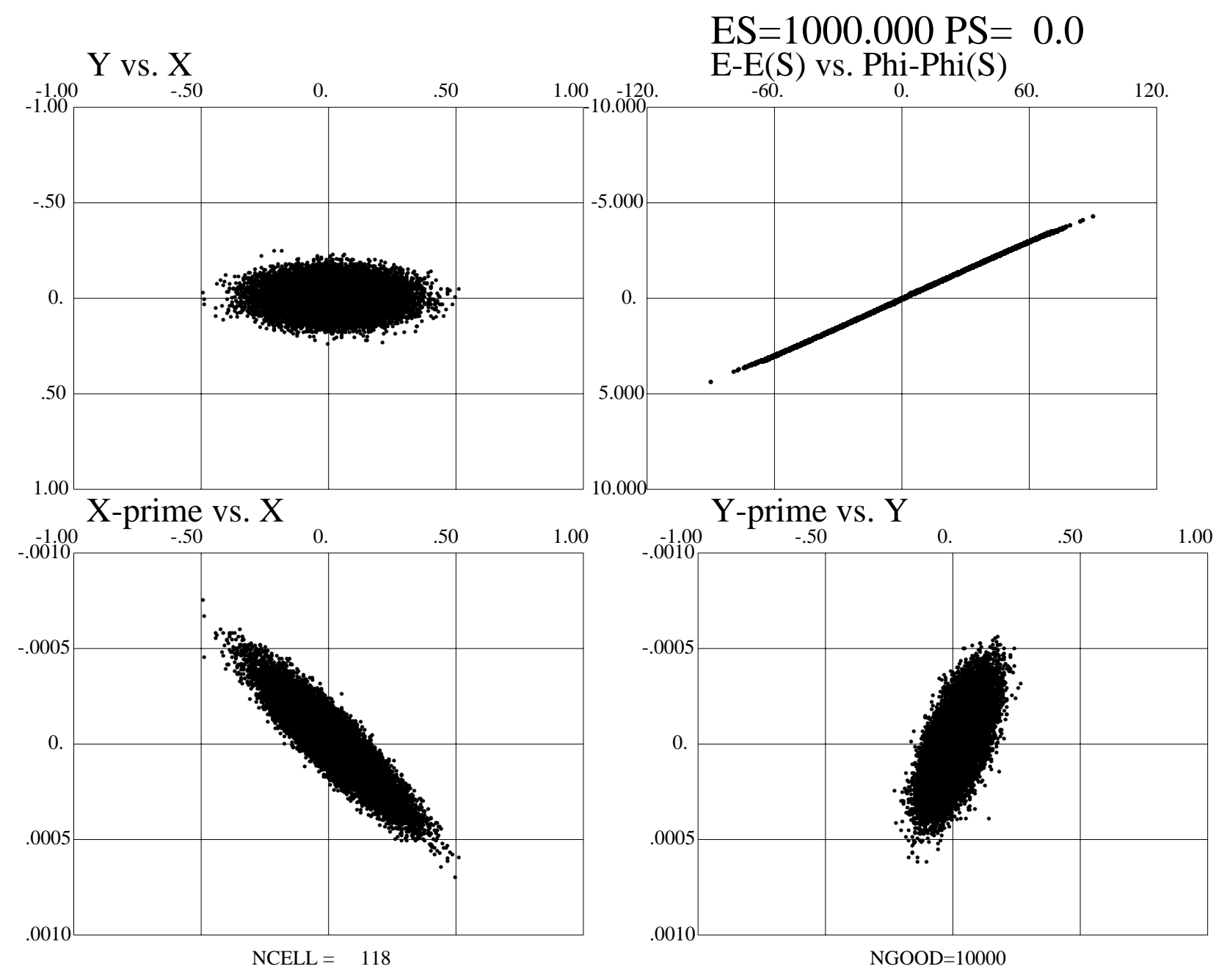

SNS HEBT|052098 |90 deg bend | 60 deg phase advance per cell |dtlhebt1mw.in|

Figure 20: Beam distribution at the foil, starting at the DTL, for 1 MW. 

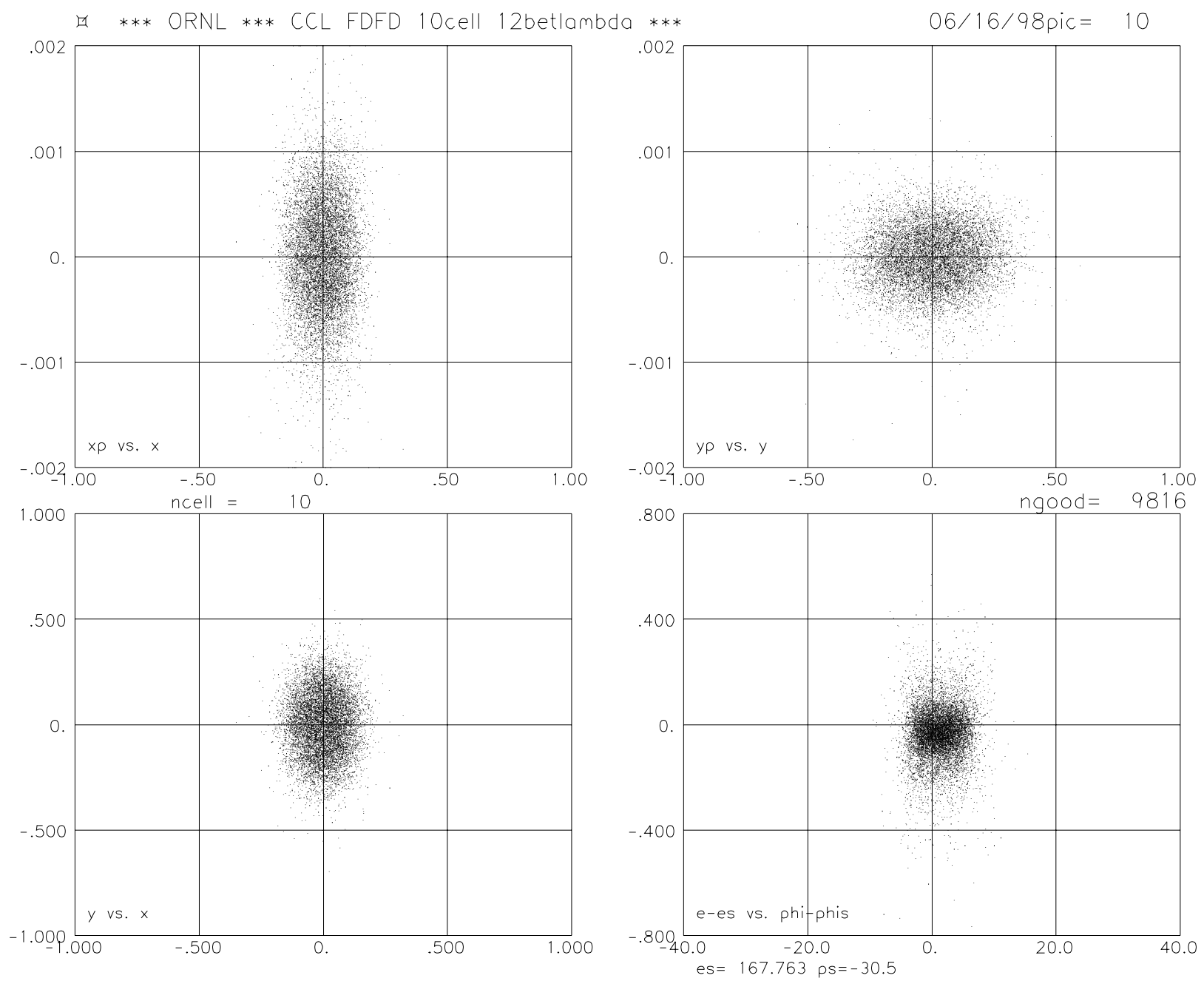

Figure 21: Beam distribution at the beginning of the CCL, starting at the RFQ, for $1 \mathrm{MW}$. 


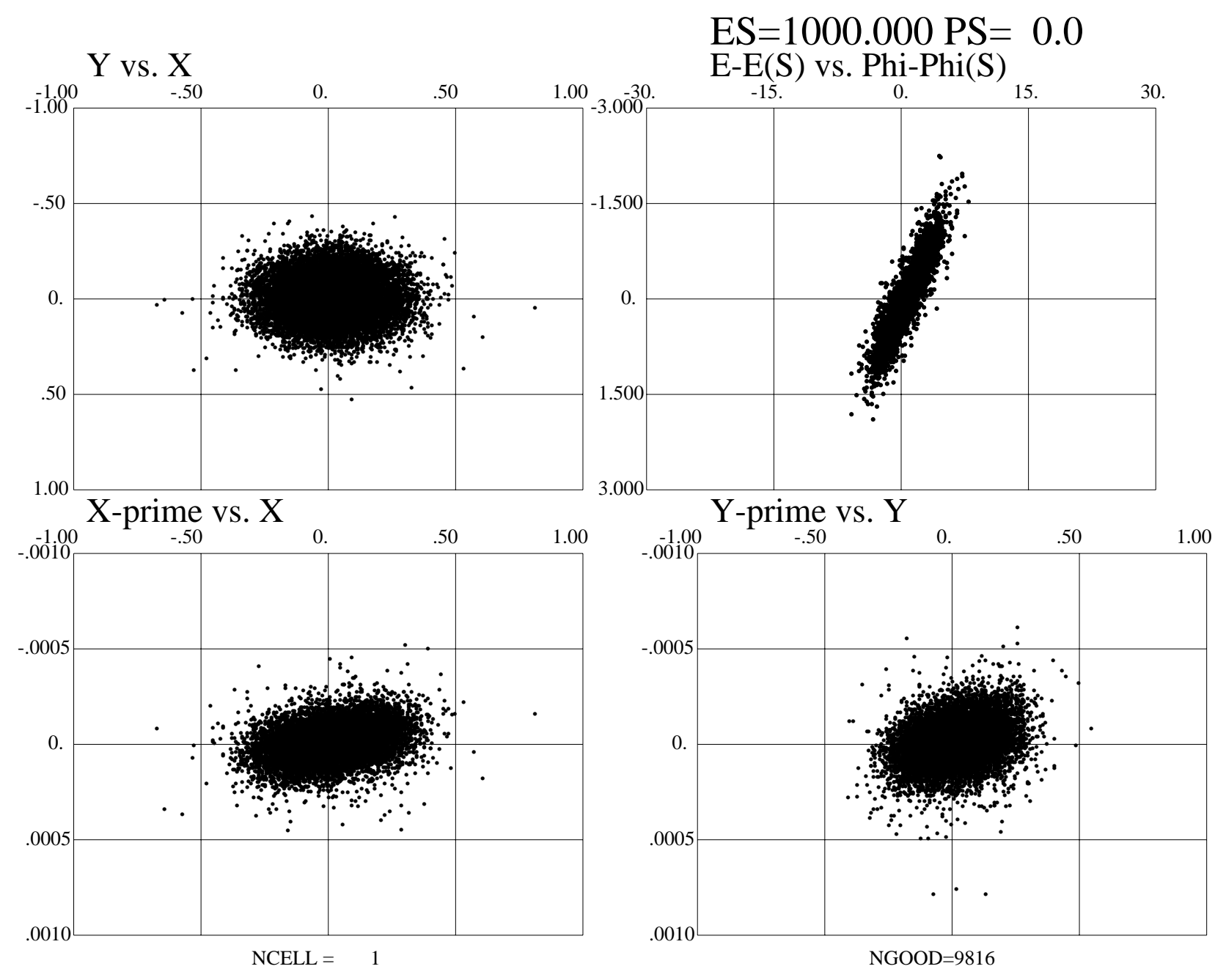

SNS HEBT| 052098 |90 deg bend | 60 deg phase advance per cell |rfqhebt1mw.in|

Figure 22: Beam distribution at the beginning of the HEBT, starting at the RFQ, for $1 \mathrm{MW}$. 


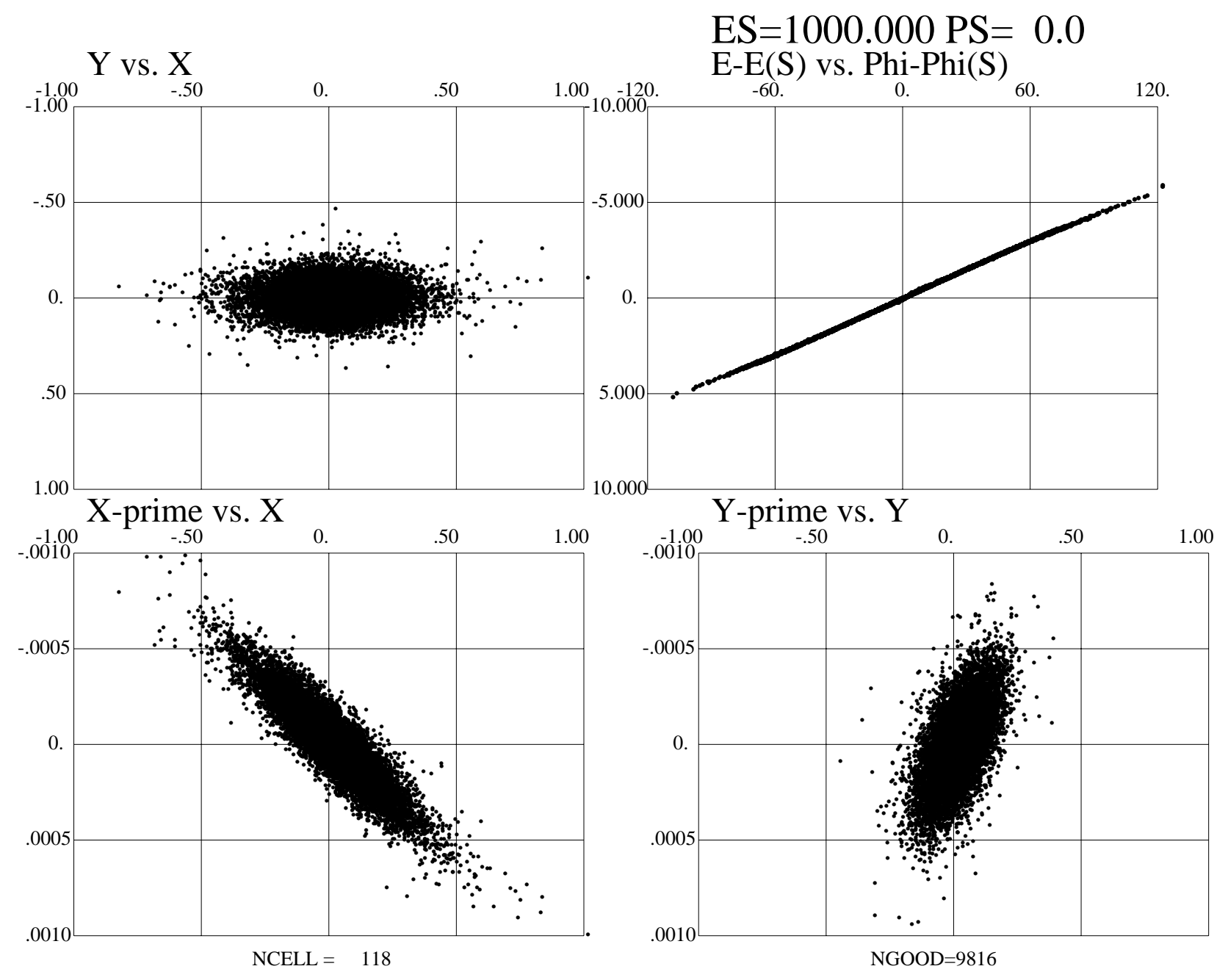

SNS HEBT| 052098 |90 deg bend | 60 deg phase advance per cell |rfqhebt1mw.in|

Figure 23: Beam distribution at the foil, starting at the RFQ, for $1 \mathrm{MW}$. 

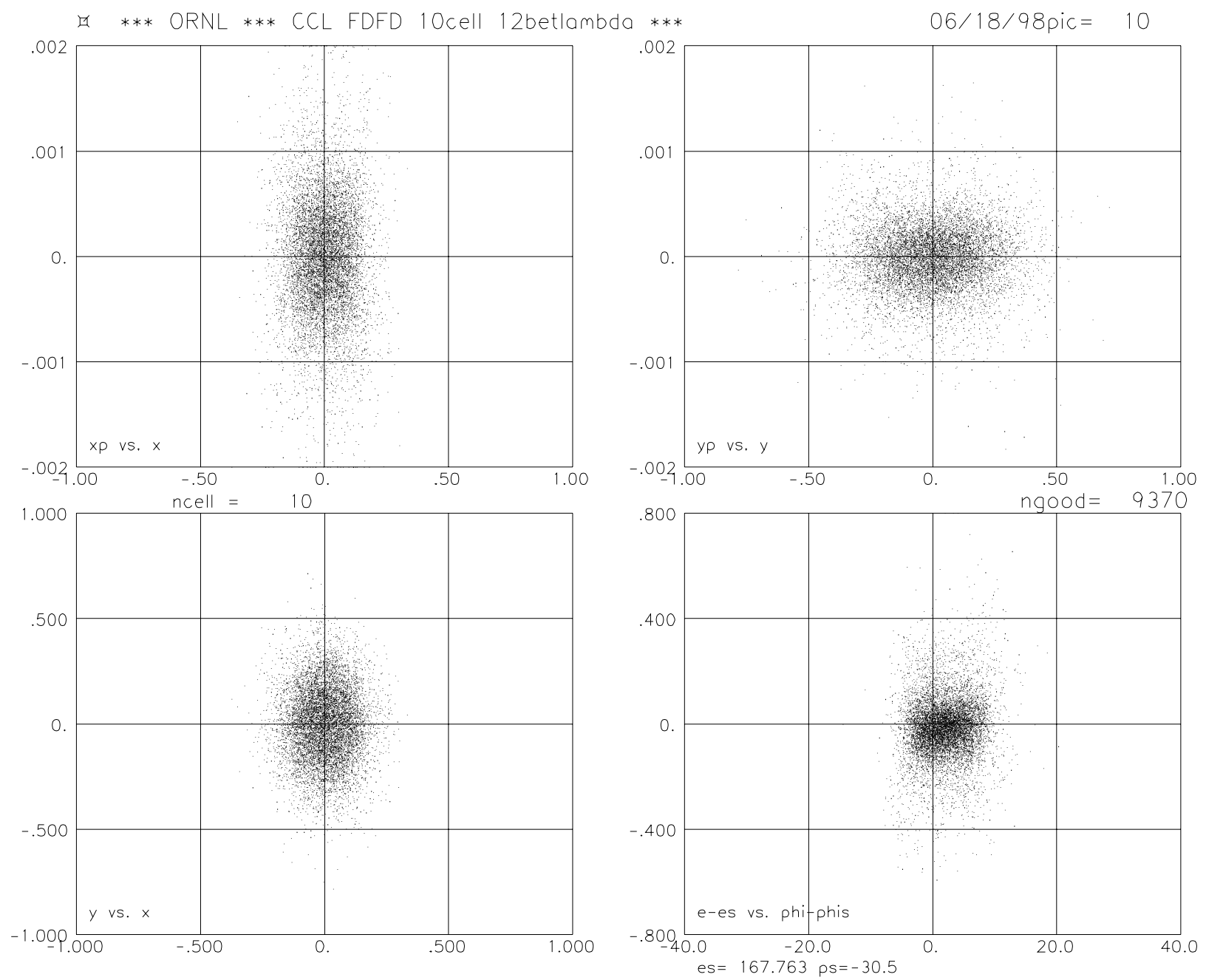

Figure 24: Beam distribution at the beginning of the CCL, starting at the DTL, for $2 \mathrm{MW}$. 


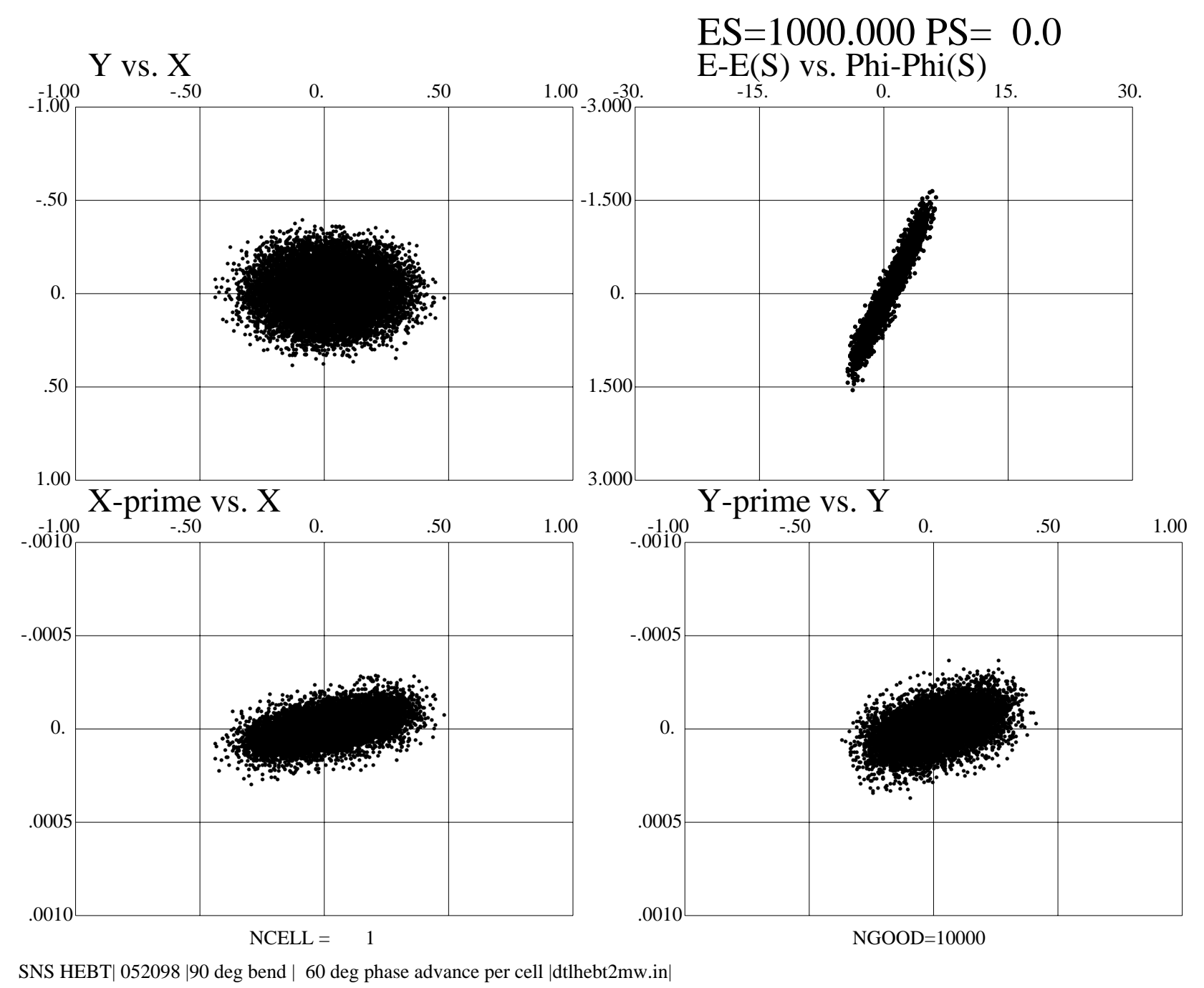

Figure 25: Beam distribution at the beginning of the HEBT, starting at the DTL, for $2 \mathrm{MW}$. 


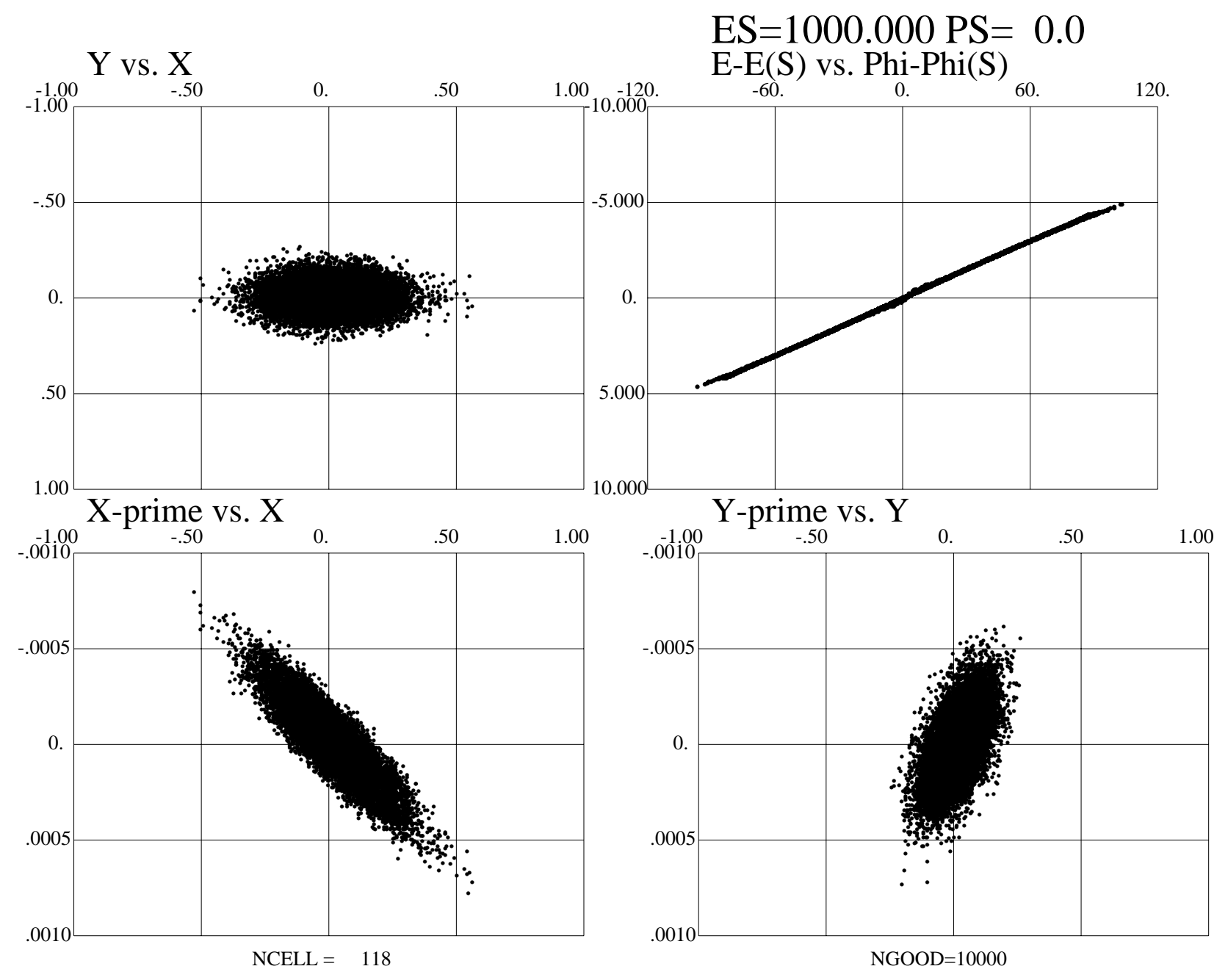

SNS HEBT 052098 |90 deg bend | 60 deg phase advance per cell |dtlhebt2mw.in|

Figure 26: Beam distribution at the foil, starting at the DTL, for 2 MW. 

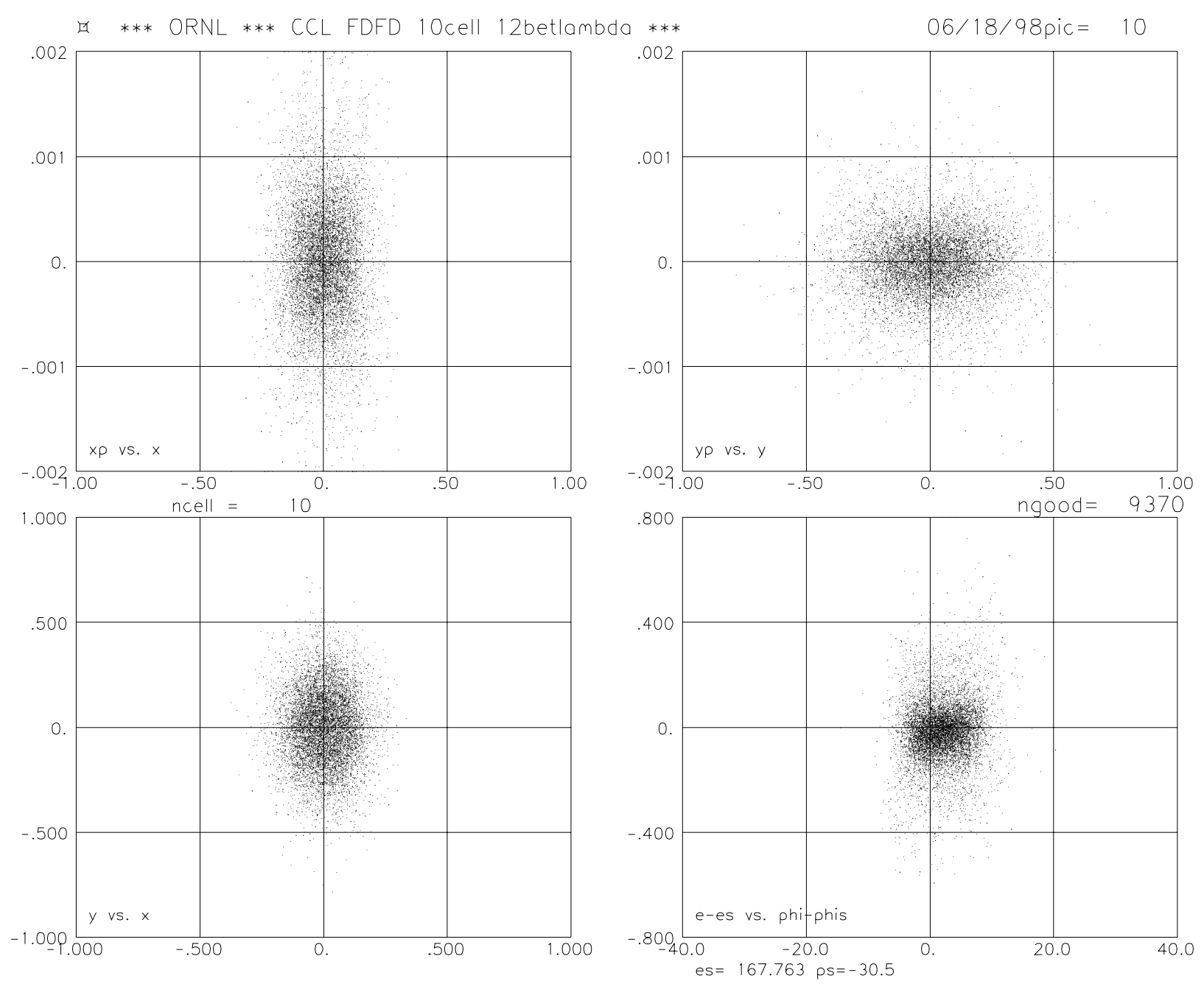

Figure 27: Beam distribution at the beginning of the CCL, starting at the RFQ, for $2 \mathrm{MW}$. 


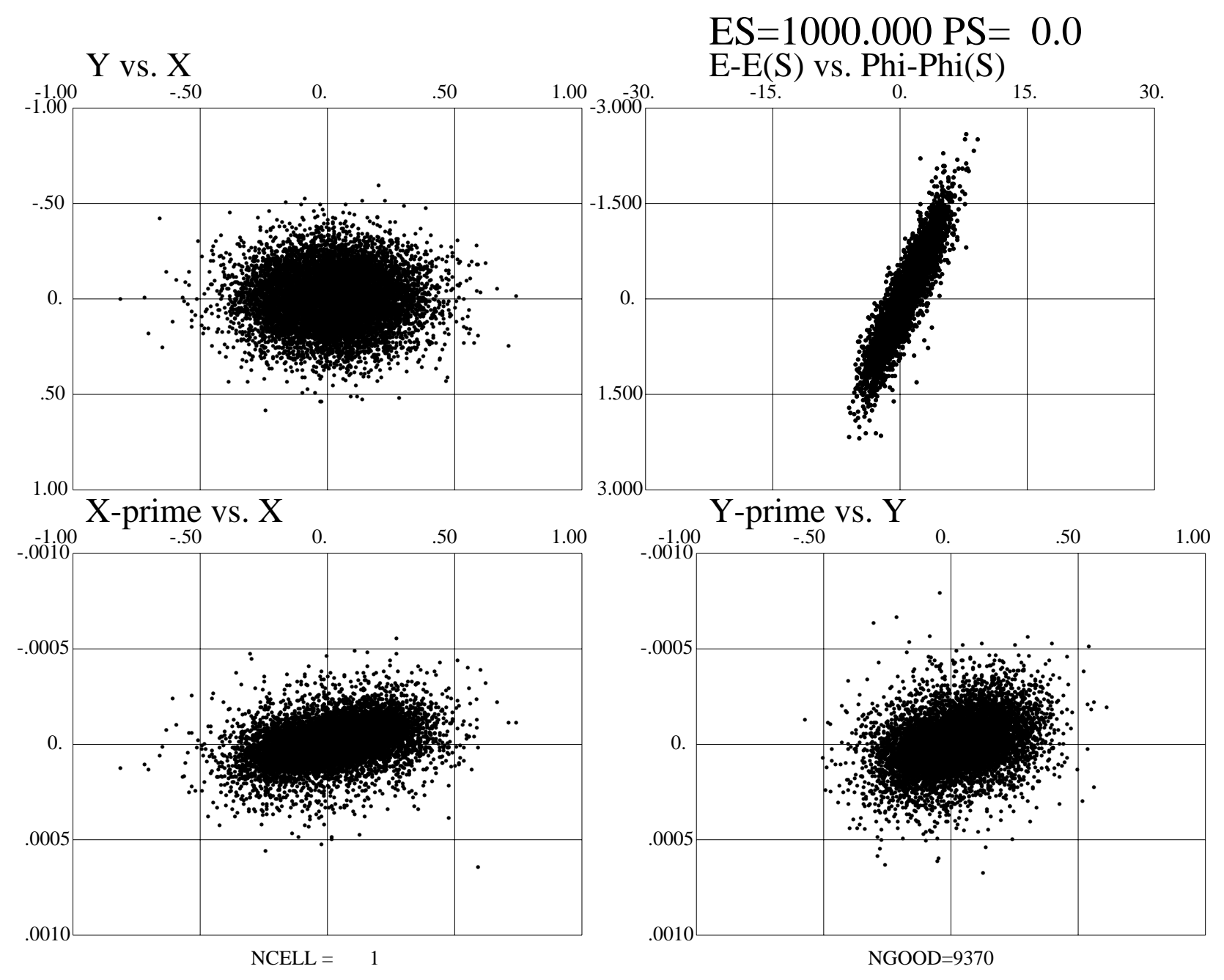

SNS HEBT| 052098 |90 deg bend | 60 deg phase advance per cell |rfqhebt2mw.in|

Figure 28: Beam distribution at the beginning of the HEBT, starting at the RFQ, for $2 \mathrm{MW}$. 


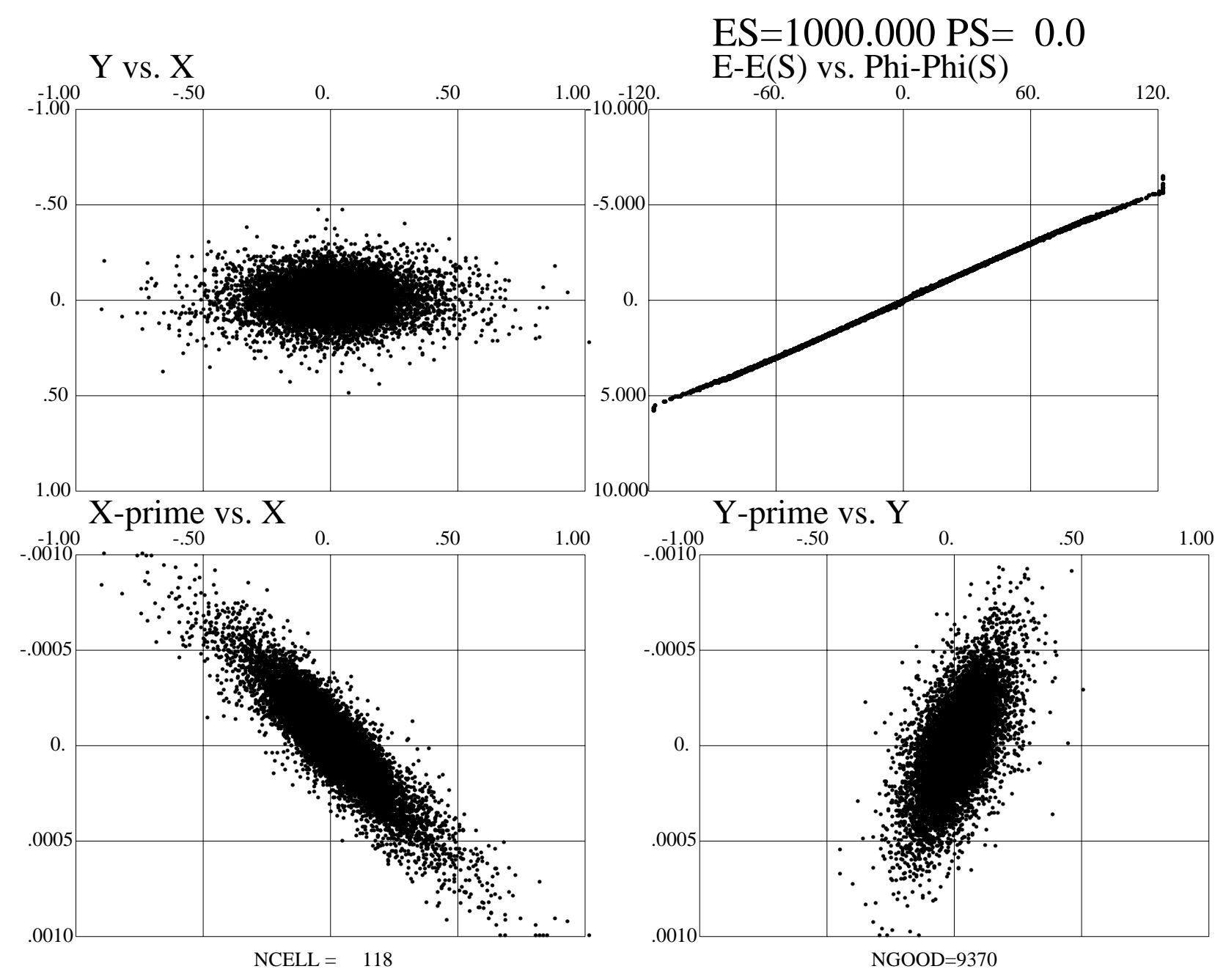

SNS HEBT| 052098 |90 deg bend | 60 deg phase advance per cell |rfqhebt2mw.in|

Figure 29: Beam distribution at the foil, starting at the RFQ, for $2 \mathrm{MW}$. 